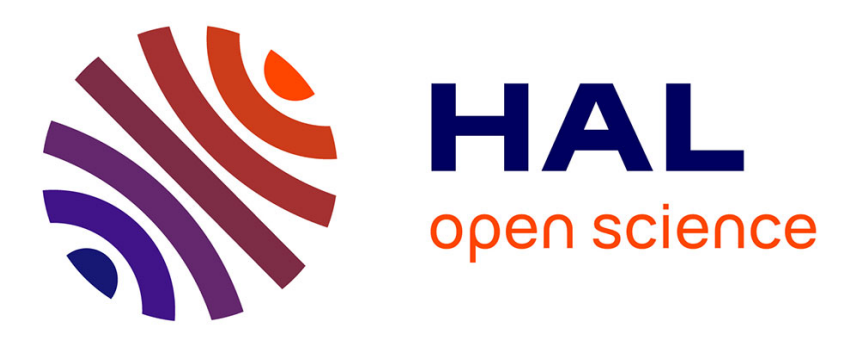

\title{
Transformation-induced plasticity in multiphase steels subjected to thermomechanical loading.
}

Denny Tjahjanto, Sergio Turteltaub, Akke S.J. Suiker, Sybrand van Der Zwaag

\section{- To cite this version:}

Denny Tjahjanto, Sergio Turteltaub, Akke S.J. Suiker, Sybrand van Der Zwaag. Transformationinduced plasticity in multiphase steels subjected to thermomechanical loading.. Philosophical Magazine, 2009, 88 (28-29), pp.3369-3387. 10.1080/14786430802438150 . hal-00513963

\section{HAL Id: hal-00513963 \\ https://hal.science/hal-00513963}

Submitted on 1 Sep 2010

HAL is a multi-disciplinary open access archive for the deposit and dissemination of scientific research documents, whether they are published or not. The documents may come from teaching and research institutions in France or abroad, or from public or private research centers.
L'archive ouverte pluridisciplinaire HAL, est destinée au dépôt et à la diffusion de documents scientifiques de niveau recherche, publiés ou non, émanant des établissements d'enseignement et de recherche français ou étrangers, des laboratoires publics ou privés. 


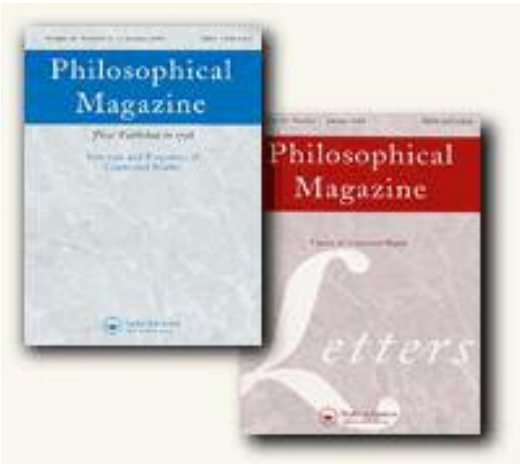

Transformation-induced plasticity in multiphase steels subjected to thermomechanical loading.

\begin{tabular}{|r|l|}
\hline Journal: & Philosophical Magazine \& Philosophical Magazine Letters \\
\hline Manuscript ID: & TPHM-08-Feb-0051.R1 \\
\hline Duthal Selection: & Philosophical Magazine \\
\hline Complete List of Authors: & $\begin{array}{l}\text { Tjahjanto, Denny; Delft University of Technology, Aerospace } \\
\text { Engineering } \\
\text { Turteltaub, Sergio; Delft University of Technology, Aerospace } \\
\text { Engineering } \\
\text { Suiker, Akke; Delft University of Technology, Aerospace } \\
\text { Engineering } \\
\text { van der Zwaag, Sybrand; Delft University of Technology, Aerospace } \\
\text { Engineering }\end{array}$ \\
\hline Keywords: & computational mechanics, plasticity of metals \\
\hline Keywords (user supplied): & $\begin{array}{l}\text { transformation-induced plasticity, Multiphase steels, } \\
\text { Thermomechanics }\end{array}$ \\
\hline
\end{tabular}

\section{ScholarONE" \\ Manuscript Central}


Philosophical Magazine

Vol. 00, No. 00, Month 2008, 1-19

\title{
RESEARCH ARTICLE
}

\section{Transformation-induced plasticity in multiphase steels subjected to thermomechanical loading}

\author{
D.D. Tjahjanto ${ }^{\dagger}$, S. Turteltaub*, A.S.J. Suiker and S. van der Zwaag \\ Faculty of Aerospace Engineering, Delft University of Technology \\ Kluyverweg 1, 2629 HS Delft, the Netherlands \\ \{Email: S.R.Turteltaub,A.S.J.Suiker,S.vanderZwaag\}@tudelft.nl
}

(v3.1 released April 2006)

\begin{abstract}
The behavior of transformation-induced plasticity steels subjected to combined thermomechanical loading is studied at the microscale by means of numerical simulations. The microstructure is composed of an austenitic phase that may deform plastically and/or transform into martensite, and a ferritic phase that may deform plastically. The micromechanical models capturing these effects are derived from a thermodynamical framework, which has been extended from previous works in order to adequately account for the thermal contributions to the kinematics and the Helmholtz energy. The models are used in numerical simulations on a polycrystalline sample composed of an aggregate of multiple austenitic and ferritic grains of various orientations. The thermomechanical response of the sample is studied under (i) isothermal straining at different temperatures above the martensitic start temperature, and under (ii) different paths of straining and cooling to temperatures below the martensitic start temperature. The first type of analysis shows that at lower temperatures the transformation mechanism is more dominant than the plasticity mechanism, whereas the converse occurs at higher temperatures. The second type of analysis illustrates that, in comparison to a benchmark initially stress-free sample at room temperature, the transformation rate under straining is higher when performed on an pre-cooled sample, but that the transformation rate under cooling is lower when carried out on a pre-strained sample. The results of this analysis indicate that, for optimizing the formability of this class of steels, it is recommendable to make a judicious choice regarding the thermomechanical loading parameters during manufacturing processes.
\end{abstract}

\section{Introduction}

Multiphase steels assisted by transformation-induced plasticity (i.e., TRIP steels) have a superior combination of strength and ductility characteristics [1]. This is because at the microscale the grains of retained austenite in a TRIP steel microstructure may transform into martensite upon mechanical and/or thermal loading, thereby inducing plasticity in the surrounding phases, i.e., a TRIP effect is generated. In order to accurately predict the overall behavior of this class of steels during manufacturing and/or operation, a thorough knowledge of the evolution of TRIP steel microstructures under thermomechanical loading is necessary.

In the last decades, various micromechanically-based models for martensitic transformations have been developed, see e.g., [2-18]. However, these models mainly focus upon mechanically-driven martensitic transformations, without taking into account the effect of temperature variations on the transformation behavior. On the other hand, the characteristics of martensitic transformations in TRIP

${ }^{\dagger}$ Current address: Max-Planck-Institut für Eisenforschung GmbH, Max-Planck-Str. 1, 40237 Düsseldorf, Germany, D.Tjahjanto@mpie.de

${ }^{*}$ Corresponding author

ISSN: $1478-6435$ print/ISSN 1478-6443 online

(C) 2008 Taylor \& Francis

DOI: $10.1080 / 1478643$ YYxxxxxxxx

http://www.informaworld.com 
steel microstructures during cooling have been investigated in recent experimental and modeling works [19-24]. Several empirically- and thermodynamically-based models have been proposed for predicting the transformation behavior in multiphase TRIP steels subjected to cooling. The stability of retained austenite in these models is characterized by the martensitic start temperature, $M_{\mathrm{s}}$, which is a function of microstructural parameters, such as the carbon concentration and the grain size. Typically, the expression for the $M_{\mathrm{S}}$ temperature is based on the classical empirical formulation of Andrews [25]. Nevertheless, the application of such models is limited to thermally-driven martensitic transformations.

In the present work, the thermomechanical model originally proposed by Turteltaub and Suiker [26-28] and further refined by Tjahjanto et al. [29] is adapted to study the behavior of TRIP steels under thermomechanical loadings. In previous works this model has been used to study the effect of microstructural parameters on the behavior of TRIP steels [30, 31]. A modification of the model is required to account for previously neglected thermal effects on the kinematics and the Helmholtz energy. The incorporation of the thermal expansion/contraction effect in the deformation is derived in the spirit of a model for shape-memory alloys proposed by Anand and Gurtin [32]. Simulations are performed to analyze the effects of microstructural parameters on the transformation and plasticity behavior upon combinations of thermal and mechanical loadings. The outcome of the analyses provides a deeper insight into the TRIP effect in multiphase carbon steels subjected to thermomechanical loading. The occurrence of local, crystalline damage in the relatively brittle martensitic product phase is not included in the present model. This aspect has been discussed elsewhere [33, 34] for TRIP steel microstructures subjected to mechanical loading at ambient temperature.

This paper is organized as follows: The models for the thermomechanical behavior of the austenitic and ferritic phases in a TRIP steel are presented in Sections 2 and 3, respectively. The models are subsequently used in numerical simulations on TRIP steel microstructures subjected to thermomechanical loadings, as discussed in Section 4. Here, for simplicity, the differences between the ferritic and bainitic phases are ignored in the TRIP steel microstructure, and pre-existing martensite generated during the manufacturing process is not included. Concluding remarks on the simulation results are given in Section 5.

\section{Thermo-elasto-plastic-transformation model for single-crystalline austenite}

\subsection{Kinematics, deformation gradients and entropy densities}

In order to quantify the different mechanisms characterizing the response of a multiphase steel, the total deformation gradient $\boldsymbol{F}$ and the entropy density $\eta$ (per unit mass) in a material point are decomposed as follows (see [29]):

$$
\boldsymbol{F}=\boldsymbol{F}_{\mathrm{e}} \boldsymbol{F}_{\mathrm{p}} \boldsymbol{F}_{\mathrm{tr}} \quad \text { and } \quad \eta=\eta_{\mathrm{e}}+\eta_{\mathrm{p}}+\eta_{\mathrm{tr}},
$$

where $\boldsymbol{F}_{\mathrm{e}}, \boldsymbol{F}_{\mathrm{p}}$ and $\boldsymbol{F}_{\mathrm{tr}}$ are, respectively, the elastic, plastic and transformation deformation gradients, see Figure 1 , and $\eta_{\mathrm{e}}, \eta_{\mathrm{p}}$ and $\eta_{\mathrm{tr}}$ are the conservative, plastic and transformation parts of the entropy density, respectively. Each material point is meant to represent an infinitesimal neighborhood that may contain a mixture of austenite and one or more crystallographically distinct arrangements of martensite (referred to as transformation systems, see Figure 1). The volume fractions of the transformation systems $\alpha(=1, \ldots, M)$ at a material point $\boldsymbol{x}$ in the reference 


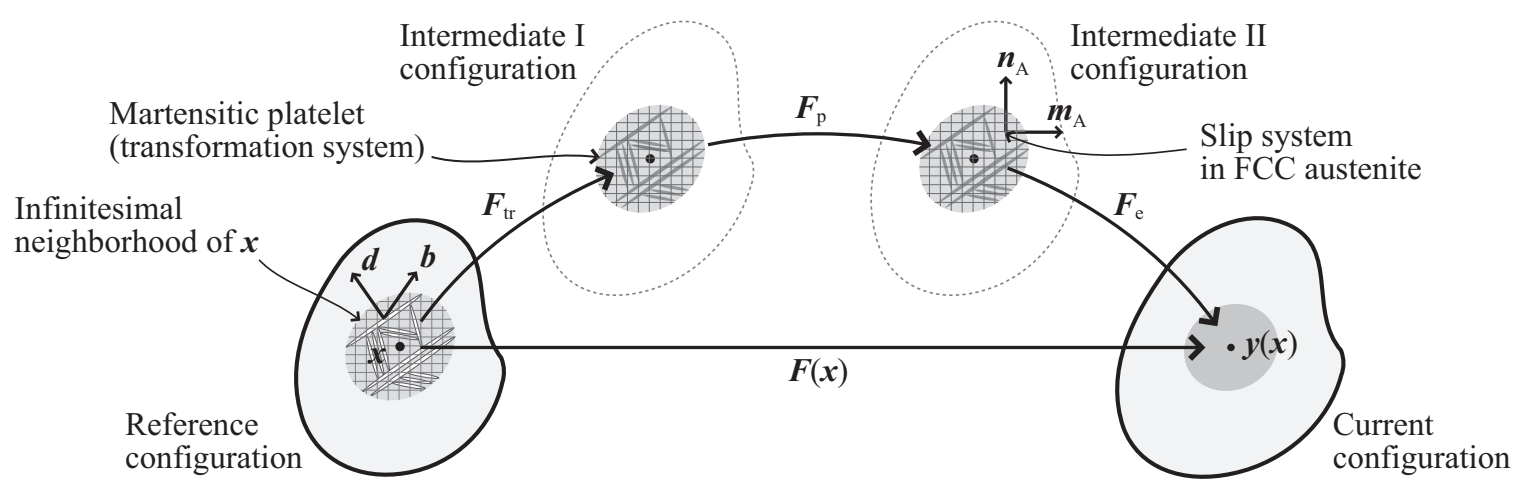

Figure 1. Schematic representation of the decomposition of the deformation gradient $\boldsymbol{F}$ into elastic-, plastic- and transformation parts and the corresponding configurations.

configuration and at time $t$ are denoted as $\xi^{(\alpha)}=\hat{\xi}^{(\alpha)}(\boldsymbol{x}, t)$, and are such that $0 \leq \xi^{(\alpha)} \leq 1$ and $0 \leq \sum_{\alpha=1}^{M} \xi^{(\alpha)} \leq 1$. The volume fraction of the (untransformed) austenite is denoted as $\xi_{\mathrm{A}}$, and is defined as $\xi_{\mathrm{A}}=1-\sum_{\alpha=1}^{M} \xi^{(\alpha)}$. In accordance with the transformation model developed in [26-28] (see also [29]), the time rate of change of the transformation deformation gradient and the transformation part of entropy density are, respectively, given by

$$
\dot{\boldsymbol{F}}_{\mathrm{tr}}=\sum_{\alpha=1}^{M} \dot{\xi}^{(\alpha)} \boldsymbol{b}^{(\alpha)} \otimes \boldsymbol{d}^{(\alpha)} \quad \text { and } \quad \dot{\eta}_{\mathrm{tr}}=\sum_{\alpha=1}^{M} \dot{\xi}^{(\alpha)} \frac{\lambda_{\mathrm{T}}^{(\alpha)}}{\theta_{\mathrm{T}}},
$$

where a superimposed dot denotes a material time derivative. The vectors $\boldsymbol{b}^{(\alpha)}$ and $\boldsymbol{d}^{(\alpha)}$ are, respectively, the transformation shape strain vector and the normal to the habit plane of a transformation system $\alpha$ (measured in the reference configuration), $\lambda_{\mathrm{T}}^{(\alpha)}$ is the latent heat of a transformation system $\alpha$ and $\theta_{\mathrm{T}}$ is the theoretical transformation temperature (i.e., the temperature at which austenite can transform isothermically into a specific system $\alpha$ of martensite at zero stress, without dissipation, and in the absence of an internal barrier). In rate form, the plastic deformation gradient, $\boldsymbol{F}_{\mathrm{p}}$, and the plastic entropy density, $\eta_{\mathrm{p}}$, are given by

$$
\boldsymbol{L}_{\mathrm{p}}=\dot{\boldsymbol{F}}_{\mathrm{p}} \boldsymbol{F}_{\mathrm{p}}^{-1}=\sum_{i=1}^{N_{\mathrm{A}}} \dot{\gamma}^{(i)} \boldsymbol{m}_{\mathrm{A}}^{(i)} \otimes \boldsymbol{n}_{\mathrm{A}}^{(i)} \quad \text { and } \quad \dot{\eta}_{\mathrm{p}}=J_{\mathrm{tr}} \sum_{i=1}^{N_{\mathrm{A}}} \dot{\gamma}^{(i)} \phi_{\mathrm{A}}^{(i)},
$$

where $\dot{\gamma}^{(i)}=\xi_{\mathrm{A}} \dot{\gamma}_{\mathrm{A}}^{(i)} / J_{\mathrm{tr}}$ represents the "effective" plastic slip rate of slip system $i$ $\left(=1, \ldots, N_{\mathrm{A}}\right)$, with $\dot{\gamma}_{\mathrm{A}}^{(i)}$ the plastic slip rate in the untransformed austenite and $J_{\mathrm{tr}}=\operatorname{det} \boldsymbol{F}_{\mathrm{tr}}$. The previous expressions are based on the assumption that plastic deformations evolve only in the (untransformed) austenitic region. Plastic deformations that occurred in the martensitic region prior to transformation are assumed to be inherited, but further deformation in the martensitic phase is modeled as elastic, in accordance with experimental observations reported in [35]. In (3), the vectors $\boldsymbol{m}_{\mathrm{A}}^{(i)}$ and $\boldsymbol{n}_{\mathrm{A}}^{(i)}$ represent, respectively, the slip direction and the slip plane normal of slip system $i$. In the second intermediate configuration, both vectors are orthogonal, unit vectors. The parameter $\phi_{\mathrm{A}}^{(i)}$ represents the change in entropy density per unit slip along slip system $i$ in the austenite.

The present model does not explicitly resolve the kinematics and kinetics at the length scale of individual dislocations (see [18] for such sub-micron model). In order to take into account the local elastic strains of the austenitic lattice associated 
with the presence of dislocations, a strain-like scalar variable $\beta$ is introduced as: $\beta:=b \sqrt{\rho_{\mathrm{d}}}$, where $b$ is the magnitude of Burger's vector and $\rho_{\mathrm{d}}$ measures the total dislocation line per unit volume (see also [36]). The rate of change of the elastic strain-like variable, $\dot{\beta}$, is taken to be linearly dependent of the rate of change of the plastic slip, $\dot{\gamma}^{(i)}$, as follows:

$$
\dot{\beta}=\sum_{i=1}^{N_{\mathrm{A}}} w^{(i)} \dot{\gamma}^{(i)}=\frac{\xi_{\mathrm{A}}}{J_{\mathrm{tr}}} \sum_{i=1}^{N_{\mathrm{A}}} w^{(i)} \dot{\gamma}_{\mathrm{A}}^{(i)}
$$

where the functions $w^{(i)}$ depend on the slip resistance, as will be discussed in Section 2.3.

\subsection{Helmholtz energy and constitutive relations}

The elastic deformation gradient $\boldsymbol{F}_{\mathrm{e}}$ that incorporates the thermal expansion (or contraction) under a temperature change from $\theta_{0}$ to $\theta$ can be expressed as

$$
\boldsymbol{F}_{\mathrm{e}}=\boldsymbol{F}_{\mathrm{e}}^{\star}\left(\boldsymbol{I}+\boldsymbol{A}\left(\theta-\theta_{0}\right)\right),
$$

where $\boldsymbol{F}_{\mathrm{e}}^{\star}$ represents the isothermal elastic deformation gradient (measured at a temperature $\theta)$, while the term $\boldsymbol{I}+\boldsymbol{A}\left(\theta-\theta_{0}\right)$ accounts for the stretch due to thermal expansion (or contraction). Here, $\boldsymbol{I}$ defines the second-order identity tensor and $\boldsymbol{A}$ is the effective thermal expansion tensor. The tensor $\boldsymbol{A}$ is obtained as the volume average of the thermal expansion tensor in the austenite and martensite in the second intermediate configuration, i.e.,

$$
\boldsymbol{A}=\frac{1}{J_{\mathrm{tr}}}\left(\xi_{\mathrm{A}} \boldsymbol{A}_{\mathrm{A}}+\left(1+\delta_{\mathrm{T}}\right) \sum_{\alpha=1}^{M} \xi^{(\alpha)} \boldsymbol{A}^{(\alpha)}\right),
$$

with $\boldsymbol{A}_{\mathrm{A}}$ and $\boldsymbol{A}^{(\alpha)}$ the thermal expansion tensors of the austenite and the martensitic transformation system $\alpha$, respectively, and $\delta_{\mathrm{T}}=\boldsymbol{b}^{(\alpha)} \cdot \boldsymbol{d}^{(\alpha)}$ the change in volume due to transformation. The thermal expansion tensors are assumed to be isotropic, and given by $\boldsymbol{A}_{\mathrm{A}}=\alpha_{\mathrm{A}} \boldsymbol{I}$ and $\boldsymbol{A}^{(\alpha)}=\alpha_{\mathrm{M}} \boldsymbol{I}$, where $\alpha_{\mathrm{A}}$ and $\alpha_{\mathrm{M}}$ are, respectively, the coefficients of thermal expansion of the austenite and martensite.

In accordance with the formulation presented in [29], the Helmholtz energy density $\psi$ (per unit mass) is taken to be a function of the state variables $\boldsymbol{F}_{\mathrm{e}}^{\star}, \theta, \beta$ and $\boldsymbol{\xi}$, where $\theta$ is the temperature and $\boldsymbol{\xi}=\left\{\xi^{(\alpha)} \mid \alpha=1, \ldots, M\right\}$ is a vector whose entries are the volume fractions of the martensitic transformation systems. Further, $\psi$ is written as the sum of the (elastic) strain energy density $\psi_{\mathrm{m}}$, the thermal energy density $\psi_{\mathrm{th}}$, the defect energy density $\psi_{\mathrm{d}}$, and the surface energy density $\psi_{\mathrm{s}}$, i.e.,

$$
\psi=\psi_{\mathrm{m}}+\psi_{\mathrm{th}}+\psi_{\mathrm{d}}+\psi_{\mathrm{s}}
$$

The elastic strain energy $\psi_{\mathrm{m}}$ is defined as a quadratic function of the elastic strain. Moreover, since the (unconstrained) thermal stretch does not contribute to the elastic strain energy density $\psi_{\mathrm{m}}$ at a temperature $\theta$, the elastic strain energy is given by

$$
\psi_{\mathrm{m}}=\frac{1}{2 \rho_{0}} J_{\mathrm{tr}} \mathbb{C} \boldsymbol{E}_{\mathrm{e}}^{\star} \cdot \boldsymbol{E}_{\mathrm{e}}^{\star}, \quad \text { where } \quad \boldsymbol{E}_{\mathrm{e}}^{\star}=\frac{1}{2}\left(\left(\boldsymbol{F}_{\mathrm{e}}^{\star}\right)^{T} \boldsymbol{F}_{\mathrm{e}}^{\star}-\boldsymbol{I}\right)
$$


In the above expressions, $\boldsymbol{E}_{\mathrm{e}}^{\star}$ defines the elastic Green-Lagrange strain measured at a temperature $\theta, \rho_{0}$ is the mass density in the reference configuration and $\mathbb{C}$ is the effective elasticity tensor, which is given by $[26,27]$

$$
\mathbb{C}=\frac{1}{J_{\mathrm{tr}}}\left(\xi_{\mathrm{A}} \mathbb{C}_{\mathrm{A}}+\left(1+\delta_{\mathrm{T}}\right) \sum_{\alpha=1}^{M} \xi^{(\alpha)} \mathbb{C}^{(\alpha)}\right)
$$

where $\mathbb{C}_{\mathrm{A}}$ and $\mathbb{C}^{(\alpha)}$ are, respectively, the elasticity tensors of the austenite and the martensitic transformation system $\alpha$. The tensor $\mathbb{C}_{\mathrm{A}}$ is characterized by three independent elastic moduli, $\kappa_{i}^{\mathrm{A}}(i=1,2,3)$ and the tensors $\mathbb{C}^{(\alpha)}$ are determined by six independent elastic moduli, $\kappa_{i}^{\mathrm{M}}(i=1, \ldots, 6)$. In addition, the elastic stiffness tensors of the austenite and martensite depend on their crystallographic orientations, see [26] for details, and may be functions of temperature; however, in the present model the temperature dependency is neglected for reasons of simplicity. For metals, the magnitude of the thermal expansion tensor $\boldsymbol{A}$ is much smaller than $\boldsymbol{E}_{\mathrm{e}}^{\star}$, hence quadratic terms in $\boldsymbol{A}$ can be ignored. Consequently, the elastic strain tensor $\boldsymbol{E}_{\mathrm{e}}^{\star}$ can be written in terms of the overall elastic Green-Lagrange strain $\boldsymbol{E}_{\mathrm{e}}$ and the thermal expansion tensor $\boldsymbol{A}$ as follows:

$$
\boldsymbol{E}_{\mathrm{e}}^{\star}=\boldsymbol{E}_{\mathrm{e}}-\boldsymbol{B}\left(\theta-\theta_{0}\right), \text { where } \quad \boldsymbol{B}=\frac{1}{2}\left(\left(\boldsymbol{F}_{\mathrm{e}}^{\star}\right)^{T} \boldsymbol{F}_{\mathrm{e}}^{\star} \boldsymbol{A}+\boldsymbol{A}\left(\boldsymbol{F}_{\mathrm{e}}^{\star}\right)^{T} \boldsymbol{F}_{\mathrm{e}}^{\star}\right)
$$

In view of $(10)_{2}, \boldsymbol{B}$ can be interpreted as the thermal expansion tensor with a correction for the elastic stretch. Observe that if the elastic deformation is relatively small, then $\boldsymbol{B} \approx \boldsymbol{A}$. From $(8)_{1}$ and $(10)_{1}$, the elastic strain energy density $\psi_{\mathrm{m}}$ can be expressed in terms of the overall elastic strain $\boldsymbol{E}_{\mathrm{e}}$, the temperature $\theta$ and the martensitic volume fractions $\boldsymbol{\xi}$, i.e.,

$$
\psi_{\mathrm{m}}\left(\boldsymbol{E}_{\mathrm{e}}, \theta, \boldsymbol{\xi}\right)=\frac{1}{2 \rho_{0}} J_{\mathrm{tr}}(\boldsymbol{\xi}) \mathbb{C}(\boldsymbol{\xi}) \boldsymbol{E}_{\mathrm{e}} \cdot\left(\boldsymbol{E}_{\mathrm{e}}-2 \boldsymbol{B}(\boldsymbol{\xi})\left(\theta-\theta_{0}\right)\right)
$$

Note that in the above expression for the elastic strain energy density $\psi_{\mathrm{m}}$ the higher-order terms in $\boldsymbol{B}$ are neglected, as well as the implicit dependency of $\boldsymbol{B}$ upon $\boldsymbol{E}_{\mathrm{e}}$ and $\theta$.

The expressions for the thermal energy $\psi_{\mathrm{th}}$, the defect energy $\psi_{\mathrm{d}}$ and the surface energy $\psi_{\mathrm{s}}$ are given by (see [29]),

$$
\begin{gathered}
\psi_{\mathrm{th}}(\theta, \boldsymbol{\xi})=h(\boldsymbol{\xi})\left(\theta-\theta_{\mathrm{T}}-\theta \ln \left(\frac{\theta}{\theta_{\mathrm{T}}}\right)\right)-\eta_{\mathrm{T}} \theta+\sum_{\alpha=1}^{M} \xi^{(\alpha)} \lambda_{\mathrm{T}}^{(\alpha)} \\
\psi_{\mathrm{d}}(\beta, \boldsymbol{\xi})=\frac{1}{2 \rho_{0}} J_{\mathrm{tr}}(\boldsymbol{\xi}) \omega_{\mathrm{A}} \mu(\boldsymbol{\xi}) \beta^{2} \quad \text { and } \quad \psi_{\mathrm{s}}(\boldsymbol{\xi})=\frac{\chi}{\ell_{0} \rho_{0}} \sum_{\alpha=1}^{M} \xi^{(\alpha)}\left(1-\xi^{(\alpha)}\right),
\end{gathered}
$$

where $\theta_{\mathrm{T}}$ is the theoretical transformation temperature, $\eta_{\mathrm{T}}$ is the conservative entropy density measured at the transformation temperature $\theta_{\mathrm{T}}, \omega_{\mathrm{A}}$ is a scaling factor for the defect energy in the austenitic phase, $\chi$ is the interface energy per unit area and $\ell_{0}$ is a length scale parameter. Furthermore, $h(\boldsymbol{\xi})$ and $\mu(\boldsymbol{\xi})$ represent the effective specific heat and the effective equivalent shear modulus, which are 
given by (see [29])

$$
h(\boldsymbol{\xi})=\xi_{\mathrm{A}} h_{\mathrm{A}}+\sum_{\alpha=1}^{M} \xi^{(\alpha)} h^{(\alpha)} \quad \text { and } \quad \mu(\boldsymbol{\xi})=\frac{1}{J_{\mathrm{tr}}}\left(\xi_{\mathrm{A}} \mu_{\mathrm{A}}+\left(1+\delta_{\mathrm{T}}\right) \sum_{\alpha=1}^{M} \xi^{(\alpha)} \mu^{(\alpha)}\right),
$$

with $h_{\mathrm{A}}$ and $h^{(\alpha)}$ being the specific heats of the austenite and martensite, respectively, and $\mu_{\mathrm{A}}$ and $\mu^{(\alpha)}$ being the equivalent isotropic shear moduli of the austenite and martensite, respectively. The complete expression for the Helmholtz energy density per unit mass follows from substituting (11), (12), (13) $)_{1}$, and $(13)_{2}$ into (7).

As pointed out in [29], the mechanical constitutive relation may be formulated in terms of the second Piola-Kirchhoff stress $\boldsymbol{S}$, where the expression follows from differentiating the Helmholtz energy with respect to the elastic Green-Lagrange strain $\boldsymbol{E}_{\mathrm{e}}$ :

$$
\boldsymbol{S}=\frac{\rho_{0}}{J_{\mathrm{tr}}} \frac{\partial \psi}{\partial \boldsymbol{E}_{\mathrm{e}}}=\mathbb{C}\left(\boldsymbol{E}_{\mathrm{e}}-\boldsymbol{B}\left(\theta-\theta_{0}\right)\right)
$$

In a similar fashion, the thermal constitutive relation in terms of the reversible entropy $\eta_{e}$ is obtained by taking the derivative of the Helmholtz energy with respect to the temperature $\theta$, leading to

$$
\eta_{\mathrm{e}}=-\frac{\partial \psi}{\partial \theta}=h \ln \left(\frac{\theta}{\theta_{\mathrm{T}}}\right)+\eta_{\mathrm{T}}+\frac{J_{\mathrm{tr}}}{\rho_{0}} \mathbb{C} \boldsymbol{E}_{\mathrm{e}} \cdot \boldsymbol{B} .
$$

It is emphasized that, in contrast to the model presented in Tjahjanto et al. [29], the mechanical constitutive relation, (15), and the thermal constitutive relation, (16), are fully coupled.

\subsection{Driving forces, kinetic relations and hardening law}

In the above section it has been shown that the Helmholtz energy contains four components, see (11), (12), $(13)_{1}$ and $(13)_{2}$. In correspondence with these four terms, the transformation driving force $f^{(\alpha)}$ for a martensitic system $\alpha$ may be decomposed as

$$
f^{(\alpha)}=f_{\mathrm{m}}^{(\alpha)}+f_{\mathrm{th}}^{(\alpha)}+f_{\mathrm{d}}^{(\alpha)}+f_{\mathrm{s}}^{(\alpha)},
$$

where $f_{\mathrm{m}}^{(\alpha)}, f_{\mathrm{th}}^{(\alpha)}, f_{\mathrm{d}}^{(\alpha)}$ and $f_{\mathrm{s}}^{(\alpha)}$ represent the (bulk) mechanical contribution, the thermal contribution, the defect energy contribution and the surface energy contribution to the transformation driving force, respectively. Using the procedure given in $[26,29]$, the bulk mechanical part of the transformation driving force can be obtained from the resolved stress contribution and the derivative of the Helmholtz energy with respect to the martensitic volume fraction, $\xi^{(\alpha)}$, as

$$
\begin{aligned}
f_{\mathrm{m}}^{(\alpha)}= & J_{\mathrm{tr}} \boldsymbol{F}_{\mathrm{p}}^{T} \boldsymbol{F}_{\mathrm{e}}^{T} \boldsymbol{F}_{\mathrm{e}} \boldsymbol{S} \boldsymbol{F}_{\mathrm{p}}^{-T} \boldsymbol{F}_{\mathrm{tr}}^{T} \cdot\left(\boldsymbol{b}^{(\alpha)} \otimes \boldsymbol{d}^{(\alpha)}\right) \\
& +\frac{1}{2}\left(\mathbb{C}_{\mathrm{A}}-\left(1+\delta_{\mathrm{T}}\right) \mathbb{C}^{(\alpha)}\right) \boldsymbol{E}_{\mathrm{e}} \cdot\left(\boldsymbol{E}_{\mathrm{e}}-2 \boldsymbol{B}\left(\theta-\theta_{0}\right)\right) \\
& -\mathbb{C} \boldsymbol{E}_{\mathrm{e}} \cdot\left(\boldsymbol{B}_{\mathrm{A}}-\left(1+\delta_{\mathrm{T}}\right) \boldsymbol{B}^{(\alpha)}\right)\left(\theta-\theta_{0}\right)
\end{aligned}
$$


where $\boldsymbol{B}_{\mathrm{A}}$ and $\boldsymbol{B}^{(\alpha)}$ represent the thermal expansion tensors that include elastic stretch corrections of the austenite and the martensitic system $\alpha$, respectively, as given by

$$
\begin{array}{r}
\boldsymbol{B}_{\mathrm{A}}=\frac{1}{2}\left(\left(\boldsymbol{F}_{\mathrm{e}}^{\star}\right)^{T} \boldsymbol{F}_{\mathrm{e}}^{\star} \boldsymbol{A}_{\mathrm{A}}+\boldsymbol{A}_{\mathrm{A}}\left(\boldsymbol{F}_{\mathrm{e}}^{\star}\right)^{T} \boldsymbol{F}_{\mathrm{e}}^{\star}\right), \\
\boldsymbol{B}^{(\alpha)}=\frac{1}{2}\left(\left(\boldsymbol{F}_{\mathrm{e}}^{\star}\right)^{T} \boldsymbol{F}_{\mathrm{e}}^{\star} \boldsymbol{A}^{(\alpha)}+\boldsymbol{A}^{(\alpha)}\left(\boldsymbol{F}_{\mathrm{e}}^{\star}\right)^{T} \boldsymbol{F}_{\mathrm{e}}^{\star}\right) .
\end{array}
$$

Note that (6) and (10) 2 have been used to get the expressions in (19). From (18) it can be observed that the bulk mechanical part of the transformation driving force consists of three terms, which successively represent the resolved stress, a term reflecting the difference in elasticity stiffness between the martensite product phase and the austenite parent phase, and a term reflecting their difference in thermal expansion properties. The dominant term in the mechanical driving force is typically the resolved stress whereas the two other terms play a role only when there is a relatively large difference in stiffness and/or thermal expansion between the parent and product phases. Furthermore, in accordance with [29], the thermal contribution to the transformation driving force, and the contributions related to the defect energy and surface energy, are derived as

$$
\begin{aligned}
f_{\mathrm{th}}^{(\alpha)} & =\rho_{0} \frac{\lambda_{\mathrm{T}}^{(\alpha)}}{\theta_{\mathrm{T}}}\left(\theta-\theta_{\mathrm{T}}\right)+\rho_{0}\left(h_{\mathrm{A}}-h^{(\alpha)}\right)\left(\theta-\theta_{\mathrm{T}}-\theta \ln \left(\frac{\theta}{\theta_{\mathrm{T}}}\right)\right), \\
f_{\mathrm{d}}^{(\alpha)} & =\frac{\omega_{\mathrm{A}}}{2}\left(\mu_{\mathrm{A}}-\left(1+\delta_{\mathrm{T}}\right) \mu^{(\alpha)}\right) \beta^{2} \quad \text { and } \quad f_{\mathrm{s}}^{(\alpha)}=\frac{\chi}{\ell_{0}}\left(2 \xi^{(\alpha)}-1\right) .
\end{aligned}
$$

The dominant term in the thermal driving force is typically the thermal analogue of the resolved stress (i.e., the term related to latent heat) whereas the second term in (20) plays a role only when there is a relatively large difference in specific heats between the parent and product phases. Moreover, the contributions related to the defect energy and the surface energy play a role mainly at the nucleation stage of martensite $\left(f_{\mathrm{d}}\right.$ effectively acting as a barrier if the martensite is stiffer than the austenite and $f_{\mathrm{s}}$ acting initially as a barrier to transformation due to the energy required to form new interfaces, see [37]).

The criterion for transformation nucleation and the evolution of the martensitic volume fraction in a transformation system $\alpha$ are captured by the following kinetic relation:

$$
\dot{\xi}^{(\alpha)}= \begin{cases}\dot{\xi}_{0} \tanh \left(\frac{f^{(\alpha)}-f_{\mathrm{cr}}^{(\alpha)}}{\nu f_{\mathrm{cr}}^{(\alpha)}}\right) & \text { if } f^{(\alpha)}>f_{\mathrm{cr}}^{(\alpha)} \\ 0 & \text { otherwise }\end{cases}
$$

where $f_{\mathrm{cr}}^{(\alpha)}$ is the critical value for the transformation driving force, $\dot{\xi}_{0}$ defines the maximum transformation rate and $\nu$ is a viscosity-like parameter. The parameters $\dot{\xi}_{0}$ and $\nu$ characterize the rate-dependent behavior of the above kinetic model.

For TRIP steels it is realistic to assume that plastic deformations evolve in the austenite only, and not in the martensite [35], i.e., the martensite deforms elastically. In the present study the evolution of plastic slip in the austenite is described by a power-law kinetic relation, where the rate of plastic slip in the 
austenite, $\dot{\gamma}_{\mathrm{A}}^{(i)}$, depends on the corresponding driving force for plasticity, $g_{\mathrm{A}}^{(i)}$, as [29]

$$
\dot{\gamma}_{\mathrm{A}}^{(i)}= \begin{cases}\dot{\gamma}_{0}^{\mathrm{A}}\left(\left(\frac{g_{\mathrm{A}}^{(i)}}{s_{\mathrm{A}}^{(i)}}\right)^{\left(1 / p_{\mathrm{A}}\right)}-1\right) & \text { if } g_{\mathrm{A}}^{(i)}>s_{\mathrm{A}}^{(i)}, \\ 0 & \text { otherwise }\end{cases}
$$

where $\dot{\gamma}_{0}^{\mathrm{A}}, p_{\mathrm{A}}$ and $s_{\mathrm{A}}^{(i)}$ are the reference slip rate, the rate-sensitivity exponent and the resistance against plastic slip in slip system $i$. Using the procedure presented in [29], the total driving force for plasticity in the austenite can be computed from the resolved stress contribution (and its thermal analogue) and the derivative of the Helmholtz energy with respect to the slip rate as

$$
g_{\mathrm{A}}^{(i)}=\boldsymbol{F}_{\mathrm{e}}^{T} \boldsymbol{F}_{\mathrm{e}} \boldsymbol{S} \cdot\left(\boldsymbol{m}_{\mathrm{A}}^{(i)} \otimes \boldsymbol{n}_{\mathrm{A}}^{(i)}\right)+\rho_{0} \theta \phi_{\mathrm{A}}^{(i)}-\omega_{\mathrm{A}} \mu \beta w^{(i)} .
$$

Observe that the third term in the plastic driving force is always negative, hence it can also be interpreted as a hardening effect (i.e., an increase in difficulty to achieve plastic slip as more dislocations are generated).

The rate of change of the slip resistance, $\dot{s}_{\mathrm{A}}^{(i)}$, is constitutively connected to the rate of plastic slip in the austenite as [29]

$$
\dot{s}_{\mathrm{A}}^{(i)}=\sum_{j=1}^{N_{\mathrm{A}}} H_{\mathrm{A}}^{(i, j)} \dot{\gamma}_{\mathrm{A}}^{(j)}
$$

Here, $H_{\mathrm{A}}^{(i, j)}$ is the hardening matrix, which is characterized by self- and crosshardening contributions, i.e.,

$$
H_{\mathrm{A}}^{(i, j)}=\left\{\begin{array}{ll}
k_{\mathrm{A}}^{(j)} & \text { for } i=j, \\
q_{\mathrm{A}} k_{\mathrm{A}}^{(j)} & \text { for } i \neq j,
\end{array} \quad \text { with } \quad k_{\mathrm{A}}^{(j)}=k_{0}^{\mathrm{A}}\left(1-\frac{s_{\mathrm{A}}^{(j)}}{s_{\infty}^{\mathrm{A}}}\right)^{u_{\mathrm{A}}}\right.
$$

where $q_{\mathrm{A}}$ is the latent hardening ratio, which reflects the ratio between the crossand self-hardening moduli on each slip system, $k_{0}^{\mathrm{A}}$ is the reference hardening modulus, $s_{\infty}^{\mathrm{A}}$ is the saturation value of the slip resistance, and $u_{\mathrm{A}}$ is the hardening exponent.

In equation (4) it has been assumed that the rate of change of the microstrain parameter, $\dot{\beta}$, is connected to the rate of change of plastic slip, $\dot{\gamma}^{(i)}$, through the functions $w^{(i)}$. In principle, a purely kinematical model can be constructed for the functions $w^{(i)}$. Alternatively, in the present study the kinetic model proposed by Clayton [36] is adopted, where the rate of change of the microstrain $\dot{\beta}_{\mathrm{A}}$ in the austenitic region is constitutively related to the average value of the rate of change of the slip resistance in the austenite, $\dot{s}_{\mathrm{A}}^{(i)}$, i.e.,

$$
\frac{1}{N_{\mathrm{A}}} \sum_{i=1}^{N_{\mathrm{A}}} \dot{s}_{\mathrm{A}}^{(i)}=c_{\mathrm{A}} \mu_{\mathrm{A}} \dot{\beta}_{\mathrm{A}}
$$

with $c_{\mathrm{A}}$ a dimensionless scaling factor. From (4), (25), (27) and the relation $\dot{\beta}=$ $\xi_{\mathrm{A}} \dot{\beta}_{\mathrm{A}} / J_{\mathrm{tr}}$, it follows that the functions $w^{(i)}$ can be related to the hardening moduli 
as

$$
w^{(i)}=\frac{1}{c_{\mathrm{A}} \mu_{\mathrm{A}} N_{\mathrm{A}}} \sum_{j=1}^{N_{\mathrm{A}}} H_{\mathrm{A}}^{(j, i)} .
$$

\section{Thermo-elasto-plastic model for single-crystalline ferrite}

The decomposition of the total deformation gradient and the entropy in the thermoelasto-plastic model for single-crystalline ferrite can be formulated in a similar fashion as in the thermo-elasto-plasto-transformation model for austenite, given in Section 2, by suppressing the transformation contribution. Formally, this can be achieved by eliminating the volume fractions as state variables, and by setting $\boldsymbol{F}_{\mathrm{tr}}=\boldsymbol{I}$ and $\eta_{\mathrm{tr}}=0$. In addition, analogous to (5), the elastic deformation gradient $\boldsymbol{F}_{\mathrm{e}}$ needs to include the thermal expansion/contraction under a temperature change from $\theta_{0}$ to $\theta$, in accordance with

$$
\boldsymbol{F}_{\mathrm{e}}=\boldsymbol{F}_{\mathrm{e}}^{\star}\left(\boldsymbol{I}+\boldsymbol{A}_{\mathrm{F}}\left(\theta-\theta_{0}\right)\right)
$$

where $\boldsymbol{F}_{\mathrm{e}}^{\star}$ is the elastic deformation gradient measured at a temperature $\theta$ and $\boldsymbol{A}_{\mathrm{F}}$ is the thermal expansion tensor, which is given by $\boldsymbol{A}_{\mathrm{F}}=\alpha_{\mathrm{F}} \boldsymbol{I}$, with $\alpha_{\mathrm{F}}$ the thermal expansion coefficient of ferrite. In analogy with equations (15) and (16), the mechanical and thermal constitutive relations, respectively, have the form

$$
\boldsymbol{S}=\mathbb{C}_{\mathrm{F}}\left(\boldsymbol{E}_{\mathrm{e}}-\boldsymbol{B}_{\mathrm{F}}\left(\theta-\theta_{0}\right)\right) \quad \text { and } \quad \eta_{\mathrm{e}}=h_{\mathrm{F}} \ln \left(\frac{\theta}{\theta_{\mathrm{F}}}\right)+\eta_{\mathrm{F}}+\frac{1}{\rho_{0}} \mathbb{C}_{\mathrm{F}} \boldsymbol{E}_{\mathrm{e}} \cdot \boldsymbol{B}_{\mathrm{F}},
$$

where $\mathbb{C}_{\mathrm{F}}, \rho_{0}, h_{\mathrm{F}}, \theta_{\mathrm{F}}$ and $\eta_{\mathrm{F}}$ are, respectively, the elastic stiffness tensor, the mass density, the specific heat, the reference temperature and the reference entropy of BCC ferrite. The stiffness tensor of BCC ferrite is characterized by three independent elastic moduli, $\kappa_{i}^{\mathrm{F}}(i=1,2,3)$. In $(30)_{1}, \boldsymbol{E}_{e}$ represents the elastic GreenLagrange strain and $\boldsymbol{B}_{\mathrm{F}}$ is the thermal expansion tensor of ferrite with corrections for the elastic stretch, i.e.,

$$
\boldsymbol{B}_{\mathrm{F}}=\frac{1}{2}\left(\left(\boldsymbol{F}_{\mathrm{e}}^{\star}\right)^{T} \boldsymbol{F}_{\mathrm{e}}^{\star} \boldsymbol{A}_{\mathrm{F}}+\boldsymbol{A}_{\mathrm{F}}\left(\boldsymbol{F}_{\mathrm{e}}^{\star}\right)^{T} \boldsymbol{F}_{\mathrm{e}}^{\star}\right)
$$

Furthermore, the asymmetry of slips in the twinning and anti-twinning directions, which is typical for plastic deformations in BCC crystals, can be accounted for by means of the "non-glide" stress effect, $\hat{\tau}_{\mathrm{F}}^{(i)}$, defined by $[38,39]$

$$
\hat{\tau}_{\mathrm{F}}^{(i)}=\boldsymbol{F}_{\mathrm{e}}^{T} \boldsymbol{F}_{\mathrm{e}} \boldsymbol{S} \cdot\left(\boldsymbol{m}_{\mathrm{F}}^{(i)} \otimes \hat{\boldsymbol{n}}_{\mathrm{F}}^{(i)}\right)
$$

where $\hat{\boldsymbol{n}}_{\mathrm{F}}^{(i)}$ represents the non-glide plane corresponding to slip system $i$. As pointed out in [29], the expression for the non-glide stress is formally similar to that of the resolved stress, with the normal to the non-glide plane playing an equivalent role as the normal to the slip plane. The non-glide stress is used for constructing the "effective" slip resistance $\hat{s}_{\mathrm{F}}^{(i)}$ as

$$
\hat{s}_{\mathrm{F}}^{(i)}=s_{\mathrm{F}}^{(i)}-\hat{a}^{(i)} \hat{\tau}_{\mathrm{F}}^{(i)},
$$




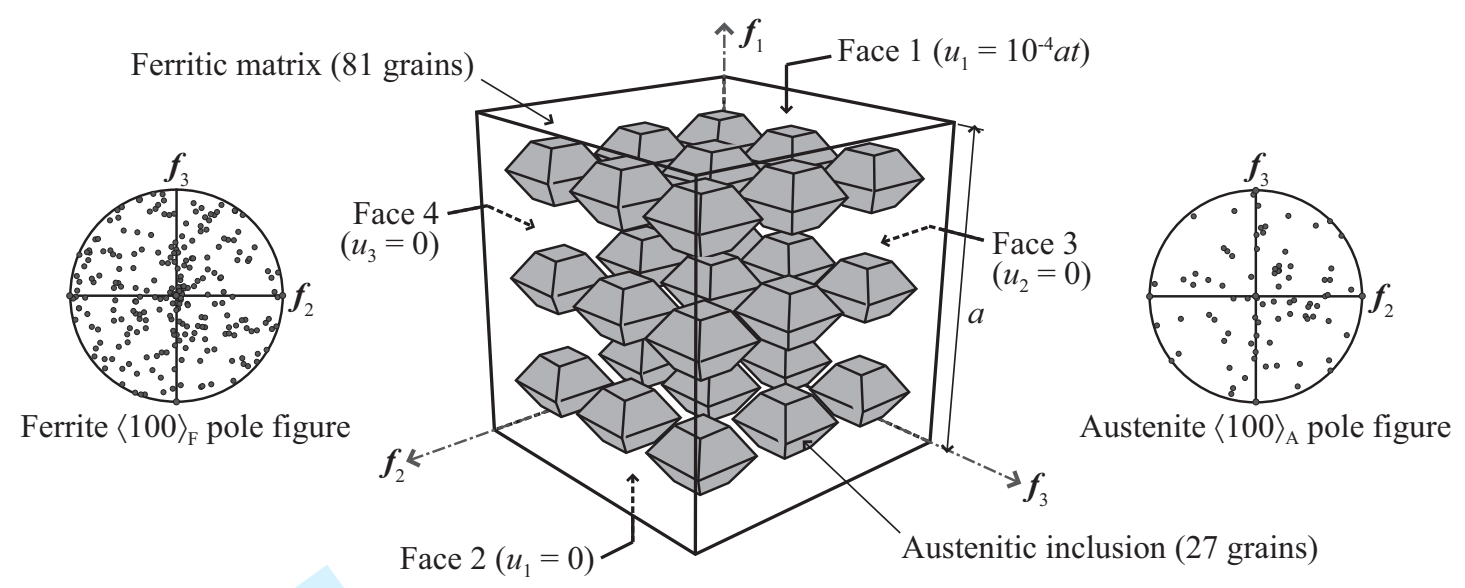

Figure 2. A polycrystalline TRIP steel sample and the applied boundary conditions that correspond to uniaxial tension. The orientations of the austenitic and ferritic grains are represented in terms of $\langle 100\rangle_{\mathrm{A}^{-}}$ and $\langle 100\rangle_{\mathrm{F}}$-pole figures.

where $s_{\mathrm{F}}^{(i)}$ is the common slip resistance, and $\hat{a}^{(i)}$ is a weight parameter that determines the net contribution of the non-glide stress to the effective slip resistance of system $i$. The expressions for the driving force and kinetic relation for plastic slip in the BCC ferrite can be obtained analogous to those for the FCC austenite in (23) and (24), by applying the following replacements

$$
\begin{aligned}
g_{\mathrm{F}}^{(i)} \rightarrow g_{\mathrm{A}}^{(i)}, \quad \boldsymbol{m}_{\mathrm{F}}^{(i)} \rightarrow \boldsymbol{m}_{\mathrm{A}}^{(i)}, \quad \boldsymbol{n}_{\mathrm{F}}^{(i)} \rightarrow \boldsymbol{n}_{\mathrm{A}}^{(i)}, \quad \hat{s}_{\mathrm{F}}^{(i)} \rightarrow s_{\mathrm{A}}^{(i)}, \quad \dot{\gamma}_{0}^{\mathrm{F}} \rightarrow \dot{\gamma}_{0}^{\mathrm{A}}, \quad p_{\mathrm{F}} \rightarrow p_{\mathrm{A}}, \\
\phi_{\mathrm{F}}^{(i)} \rightarrow \phi_{\mathrm{A}}^{(i)}, \quad \omega_{\mathrm{F}} \rightarrow \omega_{\mathrm{A}}, \quad \mu_{\mathrm{F}} \rightarrow \mu, \quad \beta_{\mathrm{F}} \rightarrow \beta, \quad \text { and } \quad w_{\mathrm{F}}^{(i)} \rightarrow w^{(i)} .
\end{aligned}
$$

Finally, the evolutions of the slip resistance $s_{\mathrm{F}}^{(i)}$ and the microstrain $\beta_{\mathrm{F}}$ are described by similar laws as those used for the FCC austenite, see equations (25)-(28).

\section{Simulation of TRIP-assisted steel behavior under thermomechanical loading}

\subsection{Microstructural sample and material parameters}

In this section, simulations are performed on microstructural TRIP steel samples subjected to thermomechanical loading. The microstructural samples contain 27 polyhedral grains of (retained) austenite with random crystallographic orientations. All austenitic grains have the same volume and the same carbon concentration (i.e., 1.4 wt. \%), and are distributed uniformly in a matrix constructed of 81 randomly-oriented grains of ferrite, see Figure 2, where the random crystallographic orientations assigned to the austenitic and ferritic grains are represented in $\langle 100\rangle_{\mathrm{A}}$ and $\langle 100\rangle_{\mathrm{F}}$ pole figures, respectively. The grains of retained austenite occupy $13 \%$ of the initial, undeformed sample volume.

Observe that the sample is only qualitatively representative of a TRIP microstructure since, in an actual sample, the grains are typically not randomly oriented and some (spatial) variations are observed in grain sizes and carbon concentrations. In order to account for microstructural texture while preserving a reasonable computational time, an additional homogenization step is required (see, e.g., [40] for TRIP steels in a purely mechanical context). The simulations presented here, however, focus on interactions at the grain level.

The single-crystalline thermo-elasto-plastic-transformation model described in 
Table 1. Material parameters for the austenite/martensite model and the ferrite model.

\begin{tabular}{|ll|}
\hline Austenite/martensite & Values \\
\hline \hline Elastic moduli austenite & $\kappa_{1}^{\mathrm{A}}=286.8, \kappa_{2}^{\mathrm{A}}=166.4, \kappa_{3}^{\mathrm{A}}=145.0[\mathrm{GPa}]$ \\
\hline Elastic moduli martensite & $\kappa_{1}^{\mathrm{M}}=372.4, \kappa_{2}^{\mathrm{M}}=345.0, \kappa_{3}^{\mathrm{M}}=191.0$, \\
& $\kappa_{4}^{\mathrm{M}}=508.4, \kappa_{5}^{\mathrm{M}}=201.9, \kappa_{6}^{\mathrm{M}}=229.5[\mathrm{GPa}]$ \\
\hline Transformation shape strain and dilation & $\gamma_{\mathrm{T}}=\left\|\boldsymbol{b}^{(\alpha)}\right\|=0.1809, \delta_{\mathrm{T}}=\boldsymbol{b}^{(\alpha)} \cdot \boldsymbol{d}^{(\alpha)}=0.0391$ \\
\hline Transformation kinetic law & $\dot{\xi}_{0}=0.003 \mathrm{~s}^{-1}, \nu=0.17, f_{\mathrm{cr}}^{(\alpha)}=227 \mathrm{MPa}$ \\
\hline Surface energy & $\chi=0.2 \mathrm{~J}^{-2} \mathrm{~m}^{-2}, \ell_{0}=0.05 \mu \mathrm{m}$ \\
\hline Hardening law & $s_{\mathrm{A}, 0}=189, s_{\infty}^{\mathrm{A}}=579[\mathrm{MPa}]$, \\
& $k_{0}^{\mathrm{A}}=3 \mathrm{GPa}, u_{\mathrm{A}}=2.8, q_{\mathrm{A}}=1$ \\
\hline Plasticity kinetic law & $\dot{\gamma}_{0}^{\mathrm{A}}=0.001 \mathrm{~s}^{-1}, n_{\mathrm{A}}=0.02$ \\
\hline Defect energy & $\beta_{\mathrm{A}, 0}=0.0056, c_{\mathrm{A}}=0.5, \omega_{\mathrm{A}}=10$ \\
& $\mu_{\mathrm{A}}=67.5, \mu^{(\alpha)}=\mu_{\mathrm{M}}=98.4[\mathrm{GPa}]$ \\
\hline Thermal driving forces & $\lambda_{\mathrm{T}}^{(\alpha)}=-50.5 \mathrm{~kJ} \cdot \mathrm{kg}^{-1}, \phi_{\mathrm{A}}^{(i)}=5.13 \mathrm{~m}^{2} \cdot \mathrm{K}^{-1} \cdot \mathrm{s}^{-2}$ \\
\hline Coefficient of thermal expansion & $\alpha_{\mathrm{A}}=\alpha_{\mathrm{M}}=2.1 \times 10^{-5} \mathrm{~K}^{-1}$ \\
\hline \hline Ferrite & $\mathrm{Values}^{\mathrm{I}}$ \\
\hline \hline Elastic moduli ferrite & $\kappa_{1}^{\mathrm{F}}=233.5, \kappa_{2}^{\mathrm{F}}=135.5, \kappa_{3}^{\mathrm{F}}=118.0[\mathrm{GPa}]$ \\
\hline Thermal driving force & $\phi_{\mathrm{F}}^{(i)}=4.27 \mathrm{~m}^{2} \cdot \mathrm{K}^{-1} \cdot \mathrm{s}^{-2}$ \\
\hline Hardening law & $s_{\mathrm{F}, 0}=154, s_{\infty}^{\mathrm{F}}=412[\mathrm{MPa}]$ \\
& $k_{0}^{\mathrm{F}}=1.9 \mathrm{GPa}^{\mathrm{F}}, u_{\mathrm{F}}=2.8, q_{\mathrm{F}}=1$ \\
\hline Plasticity kinetic law & $\dot{\gamma}_{0}^{\mathrm{F}}=0.001 \mathrm{~s}^{-1}, n_{\mathrm{F}}=0.02$ \\
\hline Non-glide stress coefficient & $\hat{a}^{(i)}=0.12$ \\
\hline Defect energy & $\omega_{\mathrm{F}}=7, \beta_{\mathrm{F}, 0}=0.0056, c_{\mathrm{F}}=0.5, \mu_{\mathrm{F}}=55.0 \mathrm{GPa}$ \\
\hline Coefficient of thermal expansion & $\alpha_{\mathrm{F}}=1.7 \times 10^{-5} \mathrm{~K}^{-1}$ \\
\hline & \\
\hline
\end{tabular}

Section 2 is used to simulate the response of the austenitic region whereas the thermo-elasto-plasticity model presented in Section 3 is applied to the ferritic region. The material parameters of these models are listed in Table 1 . The values in this table are equal to those used in [29], except for the critical value of the transformation driving force $f_{\mathrm{cr}}^{(\alpha)}$ and the latent heat $\lambda_{\mathrm{T}}^{(\alpha)}$, which are taken somewhat different. The differences stem from a reinterpretation of these parameters in order to realistically simulate the onset of transformation in coupled thermomechanical problems and to adequately account for the thermomechanical coupling during transformation. Furthermore, the elasto-plastic properties of the material, e.g., the elastic moduli, the initial slip resistance and the hardening moduli, are assumed to be temperature-independent for simplicity reasons. Details on the computation of the vectors $\boldsymbol{b}^{(\alpha)}$ and $\boldsymbol{m}^{(\alpha)}$ of the 24 martensitic transformation system and a complete list of these vectors can be found in previous works [26-28]. The slip directions $\boldsymbol{m}_{\mathrm{F}}^{(i)}$, the slip plane normals $\boldsymbol{n}_{\mathrm{F}}^{(i)}$, and the non-glide plane normals $\hat{\boldsymbol{n}}_{\mathrm{F}}^{(i)}$ of the 24 slip systems in the BCC ferrite model are listed in [30].

The entropy density change per unit slip in the austenite, $\phi_{\mathrm{A}}^{(i)}$, and in the ferrite, $\phi_{\mathrm{F}}^{(i)}$, are assumed to be temperature-independent. The values of these parameters, as presented in Table 1, are consistent with the values of the thermal driving force for plasticity presented in [29], i.e., $\phi^{(i)}$ is computed from the value of $\rho_{0} \theta \phi^{(i)}$ given in [29], evaluated at $\theta=\theta_{0}=300 \mathrm{~K}$ where the mass density in the reference configuration for the austenite and ferrite is $\rho_{0}=7800 \mathrm{~kg} \cdot \mathrm{m}^{-3}$. The specific heats of the austenite and the martensitic transformation systems are assumed to be similar, i.e., $h_{\mathrm{A}} \approx h^{(\alpha)}$ for all $\alpha=1, \ldots, M$. Correspondingly, the thermal part of 
the transformation driving force in the austenite, as represented by (20), can be approximated as

$$
f_{\mathrm{th}}^{(\alpha)}(\theta) \approx \rho_{0} \frac{\lambda_{\mathrm{T}}^{(\alpha)}}{\theta_{\mathrm{T}}}\left(\theta-\theta_{\mathrm{T}}\right)
$$

The theoretical transformation temperature is estimated as $\theta_{\mathrm{T}} \approx 633 \mathrm{~K}$ [27]. The value of the latent heat $\lambda_{\mathrm{T}}^{(\alpha)}$ for the transformation from austenite to martensite (related to the temperature $\theta_{\mathrm{T}}$ ) is assumed to be equal for all transformation systems $\alpha$, i.e., $\lambda_{\mathrm{T}}^{(\alpha)}=\lambda_{\mathrm{T}}$. Furthermore, for simplicity, the values of the coefficients of thermal expansion of the austenite and martensite are assumed to be the same, $\alpha_{\mathrm{A}}=\alpha_{\mathrm{M}}$, and, together with the value for ferrite, $\alpha_{\mathrm{F}}$, are within the range of values reported in the literature (see, e.g., [41]).

\subsection{Simulation of TRIP steel sample undergoing uniaxial tensile loading at various temperature}

The sample is initially stress-free and is subsequently subjected to an isothermal uniaxial tensile loading during a time interval $0<t \leq 1000 \mathrm{~s}$, as prescribed through the following boundary conditions, see also Figure 2: (i) The normal displacement and the tangential tractions on the external faces 2,3 and 4 are set equal to zero; (ii) The normal displacement on the external face 1 is prescribed as $u_{1}=10^{-4}$ at, where $a$ is the side-length of the cubic sample, and the tangential tractions are set to zero; (iii) the remaining cube faces (5 and 6 ) are assumed to be tractionfree. The applied boundary conditions correspond to a maximum axial nominal strain of 0.1 , which develops at a constant straining rate of $10^{-4} \mathrm{~s}^{-1}$. In order to study the influence of temperature on the overall mechanical response of TRIP steels, the isothermal uniaxial tensile simulations are performed at three different temperatures, i.e., 350,300 and $250 \mathrm{~K}$.

Figure 3 depicts, respectively, the evolution of the austenitic volume fraction as a function of the average axial strain (Figure 3a), the average axial stressstrain response (Figure 3b) and the axial stress-strain responses of the individual austenitic/martensitic (Figure 3c) and ferritic (Figure 3d) phases. The effective responses in the latter two figures are obtained by averaging the local stresses and strains in the grains of austenite (which may contain martensite) and ferrite, respectively.

The numerical simulations are performed with the finite element program ABAQUS, where the martensitic transformation model for the austenitic/martensitic phases and the crystal plasticity model for the ferritic phase are implemented as a so-called "user subroutine". The numerical implementation of the transformation model is based on the formulation presented in [28], where the incremental update algorithm relies on a fully implicit Euler backward discretization and a consistent tangent operator. A robust search algorithm is used for detecting the transformation systems that are activated during thermomechanical loading. Although not described in [28], a similar search algorithm is used to identify the active slip systems in the austenitic phase. In addition, the numerical implementation of the crystal plasticity model for the ferritic phase is based on the formulation proposed in [42], where improvements taken from the numerical implementation of the transformation model [28] have been incorporated. The sample shown in Figure 2 has been discretized with approximately 8000 tetrahedral elements (about 7000 for the 81 ferritic grains and 1000 for the 27 austenitic/martensitic grains). Each grain has been assigned one of the crystal 


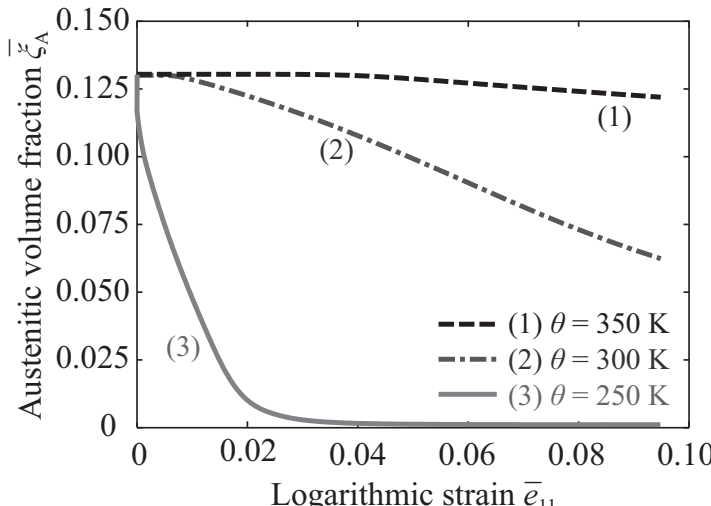

(a)

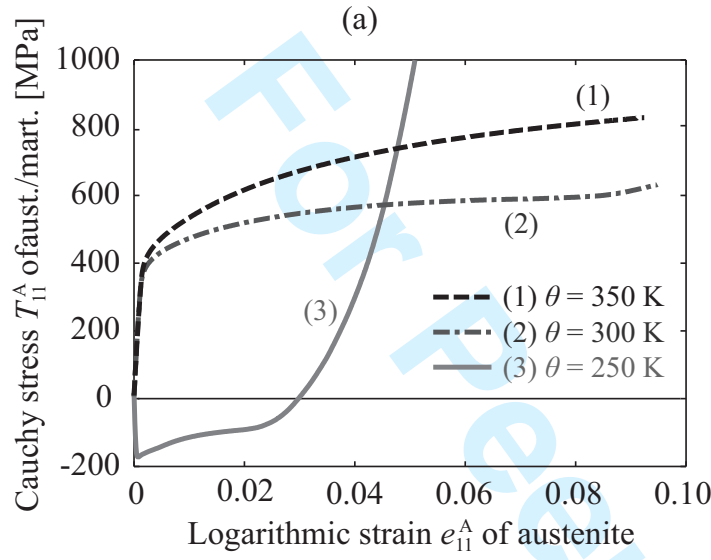

(c)

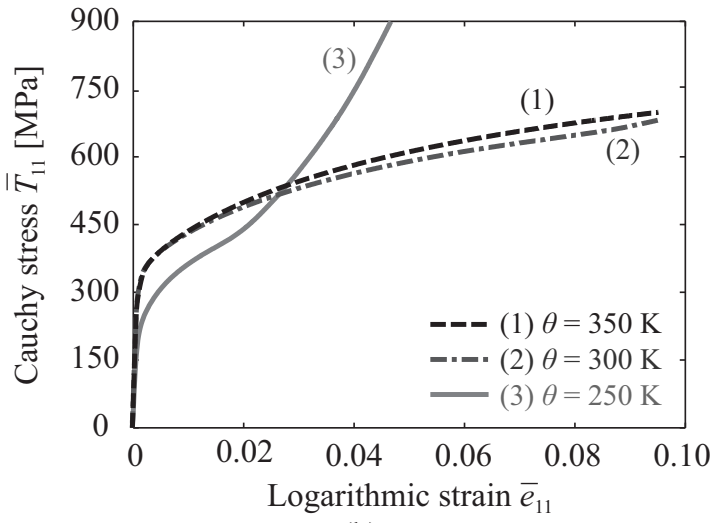

(b)

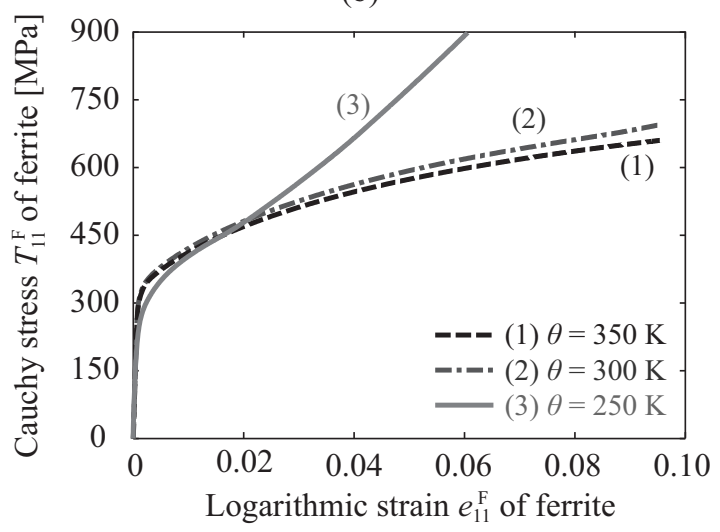

(d)

Figure 3. TRIP steel samples undergoing uniaxial tensile loading at various temperatures: (a) Evolution of austenitic volume fraction as a function of axial strain, (b) effective axial stress-strain response of the sample, (c) effective axial stress-strain response of the austenitic/martenstic phases, and (d) effective axial stress-strain response of the ferritic phase.

orientations shown in the pole figures in Figure 2

As shown in Figure 3a, under mechanical loading the transformation rate of austenite depends strongly on the temperature at which the transformation takes place. At a relatively low temperature of $250 \mathrm{~K}$ the transformation is virtually completed at about 0.04 axial deformation. In contrast, at a relatively high temperature of $350 \mathrm{~K}$ only a small portion of retained austenite has transformed into martensite at the end of the loading process (i.e., at 0.1 axial deformation). For an intermediate temperature of $300 \mathrm{~K}$, about half of the austenite has transformed into martensite at the maximum imposed strain. The dependency of the transformation rate on the temperature is due to the following two factors: Firstly, in view of (34) and since $\lambda_{\mathrm{T}}$ is negative, the thermal transformation driving force, $f_{\mathrm{th}}^{(\alpha)}$ decreases with temperature, (i.e., austenitic grains are more stable at a higher temperature), which thus makes the transformation easier at lower temperature. Secondly, the thermal contribution to the plasticity driving force, $\rho_{0} \theta \phi_{\mathrm{A}}^{(i)}$, increases with temperature, meaning that plastic flow becomes more dominant at elevated temperature. Since the development of plastic deformations retards the transformation process, the transformation occurs faster at lower temperature. As a consequence of these two factors, in the simulation at low temperature, $\theta=250 \mathrm{~K}$, the dominant inelastic mechanism in the austenite is the martensitic transformation, whereas the dominant mechanism in the simulation at high temperature, $\theta=350 \mathrm{~K}$, is plastic flow.

When comparing cases 1 and 3 in Figure 3b, it can be observed that a relatively 


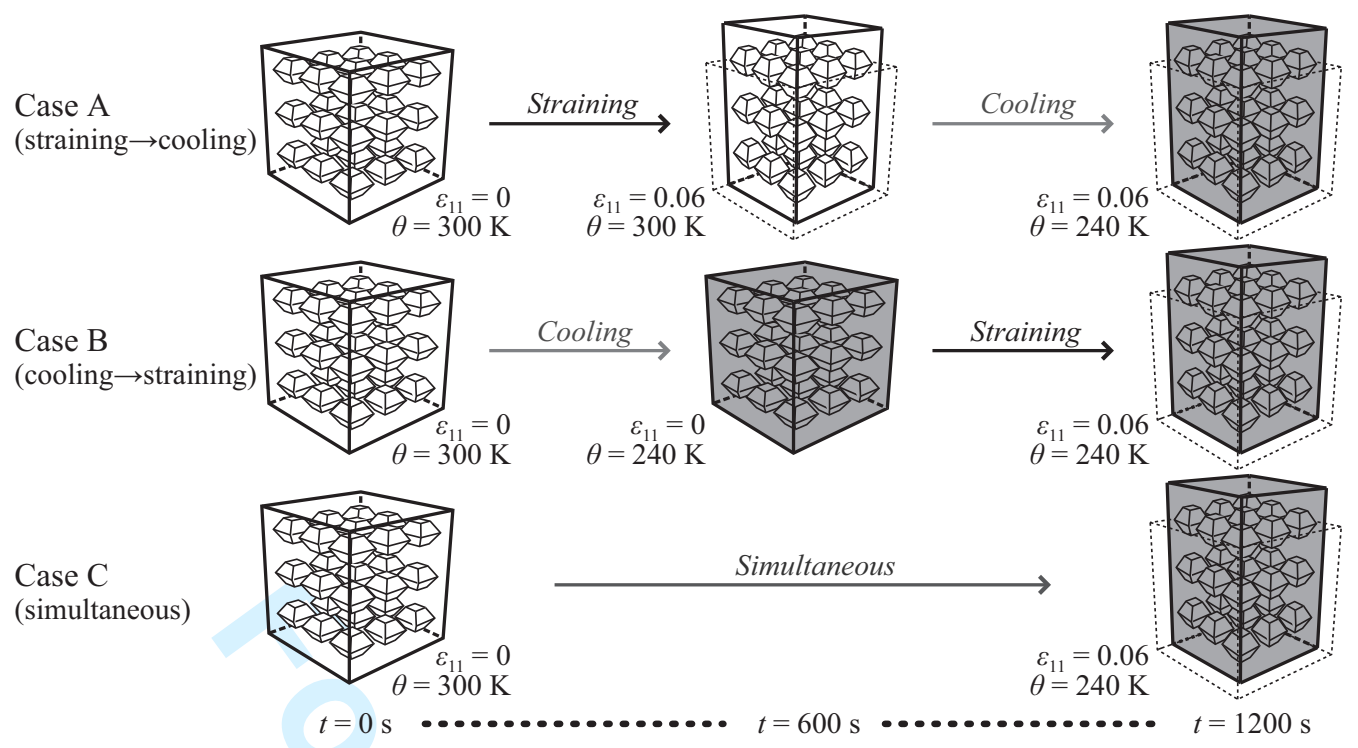

Figure 4. Three cases of TRIP steel simulations with different sequences of thermal and mechanical loadings: (A) Uniaxial straining followed by cooling, (B) cooling followed by uniaxial straining and (C) simultaneous uniaxial straining and cooling.

fast martensitic transformation for case 3 leads to an initial drop in the effective strength of the sample, followed by a significant hardening behavior. This drop in effective strength is caused by the fact the austenitic/martensitic grains for case 3 initially experience compressive axial stresses, see Figure 3c, even though the effective loading is tension. Furthermore, the substantial effective hardening for case 3 can be ascribed to a rapid transformation of the austenitic phase into a stiffer, elastic martensitic phase. Since the stresses in the elastic martensitic grains grow fast, see Figure 3c, the effective hardening of the sample is significant. Figure 3c also illustrates that at higher temperatures (i.e., cases 1 and 2) the response at the grain level typically is elasto-plastic, in correspondence with most of the untransformed austenite experiencing substantial plastic deformations. Comparing Figures $3 \mathrm{c}$ and $3 \mathrm{~d}$ shows that for cases 1 and 3 the maximum stress in the austenitic/martensitic grains is higher than in the ferritic grains, whereas for case 2 the opposite holds. Furthermore, it can be observed that for case 3 the high stresses in the austenite/martensite to some extent extent are transferred to the surrounding ferrite. Nevertheless, it is worth pointing out that the high hardening rate in case 3 might be overestimated since the damage mechanism in the martensitic phase has not been included (see $[33,34]$ ).

In metals composed of non-transforming phases, the overall strength typically increases with decreasing temperature. As shown in Figure 3b, under small axial deformations TRIP-assisted steels show the opposite trend for the considered range of temperatures. Only at larger axial deformation, when the microstructure contains a sufficient amount of martensite, the effective strength becomes the largest at the lowest temperature, $\theta=250 \mathrm{~K}$.

\subsection{Simulation of TRIP steel sample undergoing thermal and mechanical loadings}

In this section, the behavior of TRIP steel microstructures undergoing a combination of cooling and uniaxial straining is analyzed. For this purpose, three thermomechanical loading cases are considered, see Figure 4, namely (A) isothermal uniaxial straining followed by cooling, (B) cooling followed by isothermal uniax- 


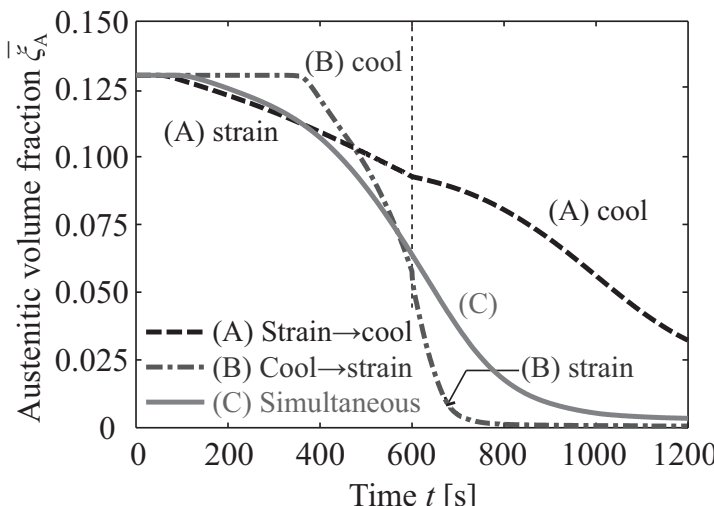

(a)

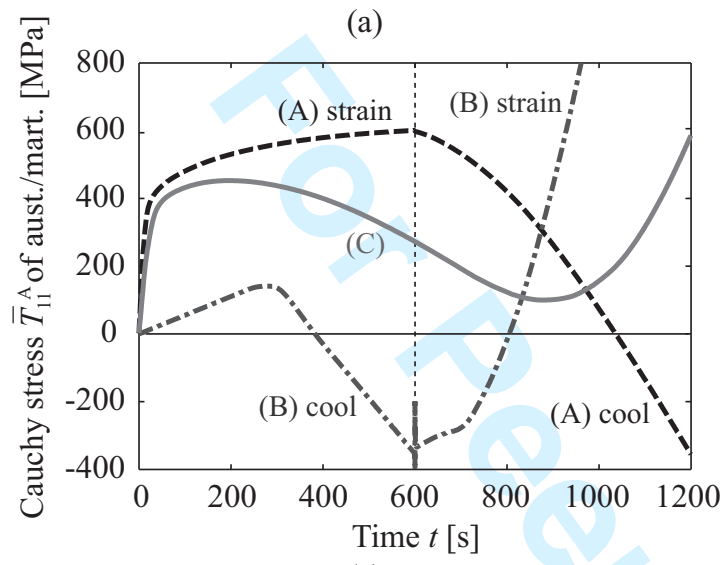

(c)

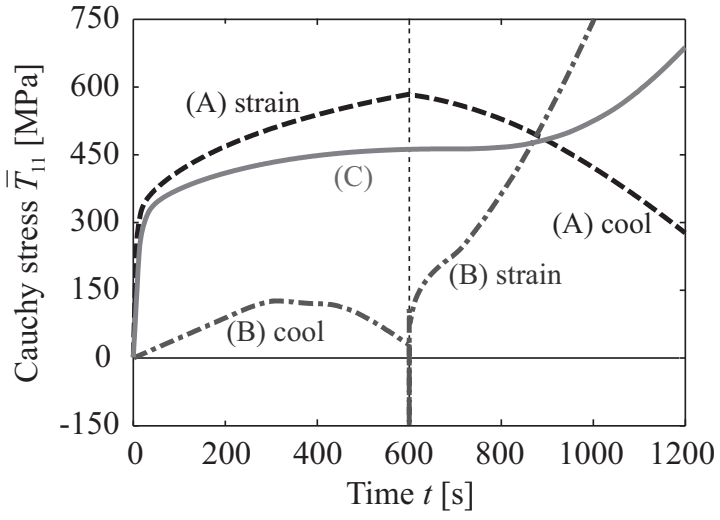

(b)

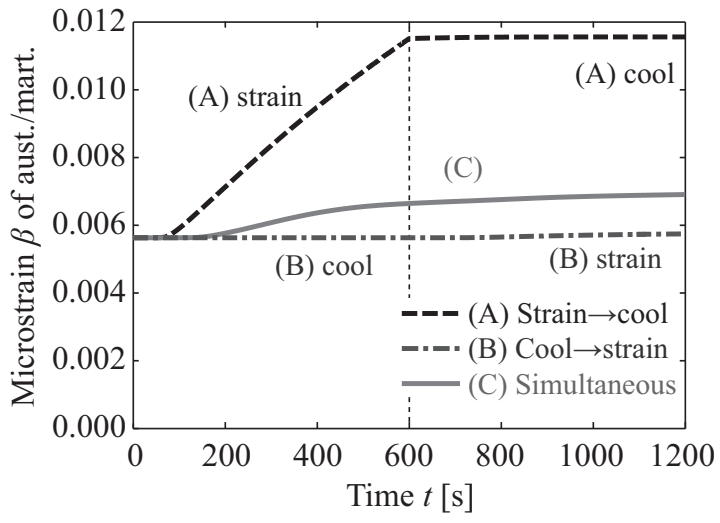

(d)

Figure 5. TRIP steel samples undergoing different paths of thermal and mechanical loadings: (a) Evolution of austenitic volume fraction, (b) evolution of effective axial stress, (c) evolution of axial stress averaged in the austenitic/martenstic phases, and (d) evolution of the microstrain averaged in the austenitic/martenstic phases.

ial straining and $(\mathrm{C})$ simultaneous uniaxial straining and cooling. In case A, the microstructural sample is first deformed up to 0.06 nominal axial strain. This is achieved by imposing the same boundary conditions as described in Section 4.2, during a time interval $0<t \leq 600 \mathrm{~s}$ (i.e., the nominal strain rate equals $10^{-4} \mathrm{~s}^{-1}$ ). The straining is applied while maintaining the temperature constant at $\theta_{0}=300$ $\mathrm{K}$. Subsequently, the sample is uniformly cooled to a temperature of $240 \mathrm{~K}$ over another period of $600 \mathrm{~s}$, in correspondence with a cooling rate of $0.1 \mathrm{~K} \cdot \mathrm{s}^{-1}$. During cooling, the normal displacement on the external face 1, see Figure 2, is kept constant (i.e., the sample is mechanically constrained in the axial direction). In case $\mathrm{B}$, the sample is first cooled to a temperature of $240 \mathrm{~K}$ over a period of $600 \mathrm{~s}$, while the normal displacement on the external face 1 is maintained at zero. Subsequently, the sample is strained up to 0.06 nominal axial strain applying the boundary conditions prescribed in Section 4.2, while the temperature is kept constant at 240 $\mathrm{K}$. In case $\mathrm{C}$, the sample is simultaneously strained and cooled over a period of $1200 \mathrm{~s}$ at nominal straining and cooling rates equal to $0.5 \times 10^{-4} \mathrm{~s}^{-1}$ and 0.05 $\mathrm{Ks}^{-1}$, respectively. Observe that the nominal straining and cooling rates used in case $\mathrm{C}$ are chosen equal to half of the values used in cases $\mathrm{A}$ and $\mathrm{B}$ in order to ease the graphical comparison between these cases. Additional simulations (not shown here) indicate that the results are qualitatively similar when using the same rates as in cases A and B during a total time of $600 \mathrm{~s}$.

The simulation results for these samples are presented in Figure 5, in terms of the evolution of the average austenitic volume fraction $\bar{\xi}_{\mathrm{A}}$ (Figure 5a), the effective axial stress response of the whole sample (Figure $5 \mathrm{~b}$ ), the effective axial stress re- 
sponse in the austenite/martensite (Figure $5 \mathrm{c}$ ), and the microstrain $\beta$ averaged in the austenitic/martensitic grains (Figure 5d). From Figure 5a it can be observed that for case A the martensitic transformation activated under straining starts relatively fast. However, upon subsequent cooling, the transformation initially slows down a little, and then gradually speeds up towards the end of the cooling process. These features for case A can be traced back to the number of martensitic transformation systems activated during the straining-cooling sequence. Initially, only a few martensitic transformation systems contribute to the overall deformation, due to a dependence of the mechanical transformation driving force upon the crystallographic orientation, see also [26, 27, 29]. During subsequent cooling, transformation proceeds for the same number of active systems but, towards the end of the cooling stage, previously inactive transformation systems start to contribute to the overall transformation mechanism. This occurs when their thermal driving force, which does not depend on crystallographic orientation, becomes substantial and the transformation barrier (i.e., the critical value for transformation) is exceeded. The activation of more transformation systems at the later cooling stage results in an increase of the transformation rate.

The transformation process for case B is activated under cooling, and starts later than for case $\mathrm{A}$, i.e., at about $t=400 \mathrm{~s}$, when the temperature is close to the martensitic start temperature $M_{\mathrm{s}}$. However, once activated, the transformation proceeds at a significantly higher rate than for case A, with all transformation systems contributing equally to the overall transformation deformation. During the subsequent straining phase, the transformation proceeds at a relatively high rate, as a result of which all austenite has transformed into martensite at the end of the loading process. The transformation evolution for case $\mathrm{C}$ lies between those for cases A and B. During the first half of the process, the transformation behavior for case $\mathrm{C}$ has a stronger similarity to that of case $\mathrm{A}$. Conversely, during the second half of the process, the transformation behavior of case $\mathrm{C}$ is closer to that of case B. This result suggests that in the simultaneous straining-cooling process, the overall transformation mechanism is dominated by the strain-driven transformation, and that the temperature-driven transformation plays a secondary role. Furthermore, comparing the first part of the curve for case A in Figure 5a to the second part of the curve for case $\mathrm{B}$, it can be observed that transformation under straining is faster when performed on a pre-cooled sample. In contrast, comparing the first part of the curve for case B to the second part of the curve for case A, it can be inferred that transformation under cooling is slower when performed on a pre-strained sample.

Figure 5b illustrates that during the straining and cooling phases of cases A and $\mathrm{B}$ the effective axial stress of the sample increases and decreases, respectively. The decrease in stress during cooling is in correspondence with the induced transformation deformation of the austenitic grains being opposed by the surrounding ferritic grains, as a result of which the austenitic/martensitic grains tend to go into compression, see Figure 5c. Since for the simultaneous straining-cooling process the overall transformation mechanism is dominated by the strain-driven transformation, the austenitic grains in this process do not reach the compressive regime, and the effective stress-strain curve does not show a drop in stress, see Figure 5b. Figure $5 \mathrm{c}$ further illustrates that at the end of the straining-cooling sequence the average axial stress in the austenitic/martensitic grains for case A corresponds to compression. In contrast, for case B at the end of the cooling-straining sequence the (mostly) martensitic grains effectively experience a large tensile stress.

The microstrain $\beta$ is used as an indicator for the accumulation of dislocations in the austenitic/martensitic regions, since $\dot{\beta}$ is related to the "effective" rates of plastic slip $\dot{\gamma}^{(i)}$ through equation (4). Note that the initial value of effective micros- 
train $\beta$ (shown in Figure 5d) coincides with the initial value of the microstrain $\beta_{\mathrm{A}}$ in the austenite (given in Table 1 ) since the sample is initially fully austenitic. This initial value, $\beta_{\mathrm{A}, 0}$, is consistently connected through (27) to the initial value of the slip resistance in the austenite, $s_{\mathrm{A}, 0}$, also shown in Table 1 (see [29] for details). Figure 5d indicates that for case A a significant amount of plastic deformation develops in the austenitic phase during straining, but that plastic flow is virtually absent during cooling. In case B almost no plastic deformation is observed in the austenite, both during cooling and straining. For case $\mathrm{C}$ the plastic deformation is moderate, and is in between that of cases A and B. Although not shown in Figure 5 , it is worth mentioning that the ferritic matrix deforms plastically during the straining phase, both in cases A and B.

The above simulation results clearly indicate that different paths of thermal and mechanical loadings give different evolutions of the transformation and plasticity processes. Accordingly, for optimizing the formability of TRIP steels, it is recommendable to make a judicious choice regarding the thermomechanical loading parameters during manufacturing processes.

\section{Concluding remarks}

Single-crystalline thermomechanical models for the austenitic/martensitic and ferritic phases in multiphase steels assisted by transformation-induced plasticity have been developed. The models have been constructed by extending the models presented in [26-29], through incorporating previously neglected thermomechanical coupling effects. Two sets of simulations have been performed to study the effective behavior of multiphase TRIP steels during thermomechanical loadings, i.e., (i) isothermal straining at different temperatures and (ii) different paths of straining and cooling. At relatively low temperature, the stability of retained austenite against transformation decreases. During isothermal straining, a lower austenite stability corresponds to a lower effective stress at which the material starts to deform inelastically. Hence, the initial effective "yield strength" of a TRIP steel sample (i.e., onset of inelastic response) decreases with temperature, which is in contrast with the trend observed for (stable) conventional steels. Nonetheless, upon continued deformation, the strength of a TRIP steel becomes the largest at the lowest temperature considered in the analyses. In addition, at low temperature the austenite transforms relatively easily with little plastic deformation, whereas at high temperature the transformation is restrained due to significant plastic deformation in the austenitic grains. Furthermore, the transformation and plastic behavior of multiphase TRIP steels is strongly dependent upon the thermomechanical loading path. Simulations of three different thermomechanical loading paths indicate that, for the strain and temperature ranges analyzed, large differences in the effective transformation rates can be realized.

\section{Acknowledgment}

This work is part of the research program of the Netherlands Institute for Metals Research (NIMR, presently known as the Materials Innovation Institute, M2i) and the Stichting voor Fundamenteel Onderzoek der Materie (FOM, financially supported by the Nederlandse Organisatie voor Wetenschappelijk Onderzoek (NWO)). The research was carried out under project number 02EMM20 of the FOM/NIMR program "Evolution of the Microstructure of Materials" (P-33). 


\section{References}

[1] P.J. Jacques, J. Ladrière, and F. Delannay. On the influence of interactions between phases on the mechanical stability of retained austenite in transformation-induced plasticity multiphase steels. Metall. Mater. Trans. A, 32:2759-2768, 2001.

[2] J.B. Leblond, G. Mottet, and J.C. Devaux. A theoretical and numerical approach to the plastic behaviour of steels during phase-transformation - I. derivation of general relations. J. Mech. Phys. Solids, 34:395-409, 1986.

[3] J.B. Leblond, G. Mottet, and J.C. Devaux. A theoretical and numerical approach to the plastic behaviour of steels during phase-transformation - II. study of classical plasticity for ideal-plastic phases. J. Mech. Phys. Solids, 34:411-432, 1986.

[4] A. Bhattacharyya and G.J. Weng. An energy criterion for the stress-induced martensitic transformation in a ductile system. J. Mech. Phys. Solids, 42:1699-1724, 1994.

[5] F. Marketz and F.D. Fischer. Micromechanical modelling of stress-assisted martensitic transformation. Modelling Simul. Mater. Sci. Eng., 2:1017-1046, 1994.

[6] F. Marketz and F.D. Fischer. A mesoscale study on the thermodynamic effect of stress on martensitic transformation. Metall. Mater. Trans. A, 26:267-278, 1995.

[7] Y. Tomita and T. Iwamoto. Constitutive modeling of TRIP steel and its application to the improvement of the mechanical properties. Int. J. Mech. Sci., 37:1295-1305, 1995.

[8] J.M. Diani, H. Sabar, and M. Berveiller. Micromechanical modelling of the transformation induced plasticity (TRIP) phenomenon in steels. Int. J. Eng. Sci., 33:1921-1934, 1995.

[9] J.M. Diani and D.M. Parks. Effects of strain state on the kinetics of strain-induced martensite in steels. J. Mech. Phys. Solids, 46(9):1613-1635, 1998.

[10] M. Cherkaoui, M. Berveiller, and H. Sabar. Micromechanical modeling of martensitic transformationinduced plasticity (TRIP) in austenitic single crystals. Int. J. Plasticity, 14:597-626, 1998.

[11] V.I. Levitas, A.V. Idesman, and E. Stein. Shape memory alloys: Micromechanical modeling and numerical analysis of structures. J. Intel. Mat. Syst. Str., 10:983-996, 1999.

[12] V.I. Levitas, A.V. Idesman, and G.B. Olson. Continuum modeling of strain-induced martensitic transformation at shear-band intersections. Acta Mater., 47(1):219-233, 1999.

[13] M. Cherkaoui, M. Berveiller, and X. Lemoine. Coupling between plasticity and martensitic phase transformation: Overall behavior of polycrystalline TRIP steels. Int. J. Plasticity, 16:1215-1241, 2000.

[14] Y. Tomita and T. Iwamoto. Computational prediction of deformation behavior of TRIP steels under cyclic loading. Int. J. Mech. Sci., 43:2017-2034, 2001.

[15] L. Taleb and F. Sidoroff. A micromechanical modeling of the greenwood-johnson mechanism in transformation induced plasticity. Int. J. Plasticity, 19(10):1821-1842, 2003.

[16] T. van Rompaey, Q. Furnémont, P.J. Jacques, T. Pardoen, B. Blanpain, and P. Wollants. Micromechanical modelling of TRIP steels. Mater. Technol., 74(6):365-369, 2003.

[17] T. van Rompaey, F. Lani, P.J. Jacques, B. Blanpain, P. Wollants, and T. Pardoen. Threedimensional computational-cell modeling of the micromechanics of the martensitic transformation in transformation-induced plastictity-aided multiphase steels. Metall. Mater. Trans. A, 37:99-107, 2006.

[18] J. Shi, S. Turteltaub, E. Van der Giessen, and J.C.C. Remmers. Discrete dislocation-transformation model for austenitic single crystals. Modelling Simul. Mater. Sci. Eng., 2008. To appear.

[19] E. Jimenez-Melero, N.H. van Dijk, L. Zhao, J. Sietsma, S.E. Offerman, J.P. Wright, and S. van der Zwaag. Martensitic transformation of individual grains in low-alloyed TRIP steels. Scripta Mater., 56:421-424, 2007.

[20] N.H. van Dijk, L. Zhao, M.Th. Rekveldt, H. Fredrikze, O. Tegus, E. Brück, J. Sietsma, and S. van der Zwaag. Neutron depolarisation study of the austenite grain size in TRIP steels. Physica B, 350:e463e466, 2004.

[21] S. van der Zwaag, L. Zhao, S.O. Kruijver, and J. Sietsma. Thermal and mechanical stability of retained austenite in aluminum-containing multiphase TRIP steels. ISIJ Int., 42(12):1565-1570, 2002.

[22] J.J. Wang and S. van der Zwaag. Stabilization mechanisms of retained austenite in transformationinduced plasticity steel. Metall. Mater. Trans. A, 32(6):1527-1539, 2001.

[23] L. Barbé, K. Conlon, and B.C. de Cooman. Characterization of the metastable austenite in low-alloy FeCMnSi (TRIP)-aided steel by neutron diffraction. Z. Metallkd., 93(12):1217-1227, 2002.

[24] L. Samek, E. de Moor, J. Penning, and B.C. de Cooman. Influence of alloying elements on the kinetics of strain-induced martensitic nucleation in low-alloy multi-phase high-strength steels. Metall. Mater. Trans. A, 37(1):109-124, 2006.

[25] K.W. Andrews. Empirical formulae for calculation of some transformation temperatures. J. Iron Steel Inst., 203:721, 1965.

[26] S. Turteltaub and A.S.J. Suiker. A multi-scale thermomechanical model for cubic to tetragonal martensitic phase transformations. Int. J. Solids Struct., 43:4509-4545, 2006.

[27] S. Turteltaub and A.S.J. Suiker. Transformation-induced plasticity in ferrous alloys. J. Mech. Phys. Solids, 53:1747-1788, 2005.

[28] A.S.J. Suiker and S. Turteltaub. Computational modelling of plasticity induced by martensitic phase transformations. Int. J. Numer. Meth. Eng., 63:1655-1693, 2005.

[29] D.D. Tjahjanto, S. Turteltaub, and A.S.J. Suiker. Crystallographically-based model for transformation-induced plasticity in multiphase carbon steels. Continuum Mech. Therm., 19(7):399$422,2008$.

[30] D.D. Tjahjanto, S. Turteltaub, A.S.J. Suiker, and S. van der Zwaag. Modelling of the effects of grain orientation on transformation-induced plasticity in multiphase steels. Modelling Simul. Mater. Sci. Eng., 14:617-636, 2006.

[31] D.D. Tjahjanto, A.S.J. Suiker, S. Turteltaub, P.E.J. Rivera Diaz del Castillo, and S. van der Zwaag. Micromechanical predictions of TRIP steel behavior as a function of microstructural parameters. 
Comp. Mater. Sci., 41(1):107-116, 2007.

[32] L. Anand and M.E. Gurtin. Thermal effects in the superelasticity of crystalline shape-memory materials. J. Mech. Phys. Solids, 51:1015-1058, 2003.

[33] A.S.J. Suiker and S. Turteltaub. Numerical modelling of transformation-induced damage and plasticity in metals. Modelling Simul. Mater. Sci. Eng., 15:S147-S166, 2007.

[34] A.S.J. Suiker and S. Turteltaub. Crystalline damage growth during martensitic phase transformations. Philos. Mag., 87(32):5033-5063, 2007.

[35] P.J. Jacques, Q. Furnémont, S. Godet, T. Pardoen, K.T. Conlon, and F. Delannay. Micromechanical characterisation of TRIP-assisted multiphase steels by in situ neutron diffraction. Philos. Mag., 86(16):2371-2392, 2006.

[36] J.D. Clayton. Dynamic plasticity and fracture in high density polycrystals: Constitutive modeling and numerical simulation. J. Mech. Phys. Solids, 53:261-301, 2005.

[37] S. Turteltaub and A.S.J. Suiker. Grain size effects in multiphase steels assisted by transformationinduced plasticity. Int. J. Solids Struct., 43:7322-7336, 2006.

[38] J.L. Bassani, K. Ito, and V. Vitek. Complex macroscopic plastic flow arising from non-planar dislocation core structures. Mat. Sci. Eng. A, 319-321:97-101, 2001.

[39] V. Vitek, M. Mrovec, and J.L. Bassani. Influence of non-glide stresses on plastic flow: From atomistic to continuum modeling. Mat. Sci. Eng. A, 365:31-37, 2004.

[40] D. Tjahjanto, F. Roters, and P. Eisenlohr. Iso-work-rate weighted-taylor homogenization scheme for multiphase steels, assisted by transformation-induced plasticity effect. Steel Res. Int., 78(10-11):777783, 2007.

[41] J. Huang, S. C. Vogel, W. J. Poole, M. Militzer, and P. Jacques. The study of low-temperature austenite decomposition in a Fe-C-Mn-Si steel using the neutron Bragg edge transmission technique. Acta Mater., 55(8):2683-2693, 2007.

[42] A.M. Cuitiño and M. Ortiz. Computational modelling of single crystals. Modelling Simul. Mater. Sci. Eng., 1:225-263, 1992. 


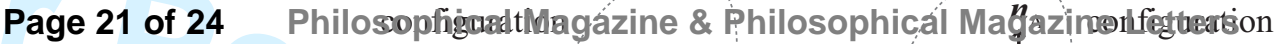

Martensitic platelet (transformation system)

Infinitesimal

neighborhood of $\boldsymbol{x}$

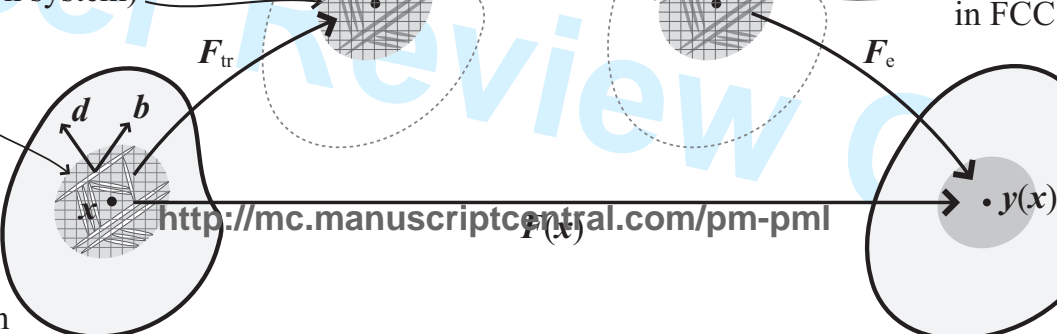




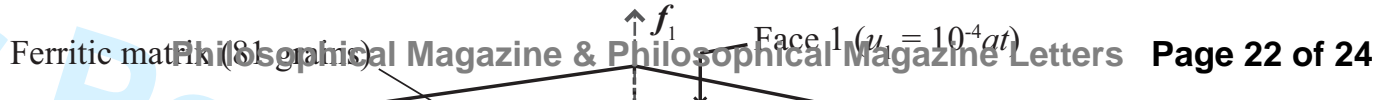

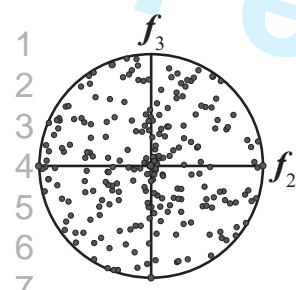

Ferrite $\langle 100\rangle_{\mathrm{F}}$ pole figure
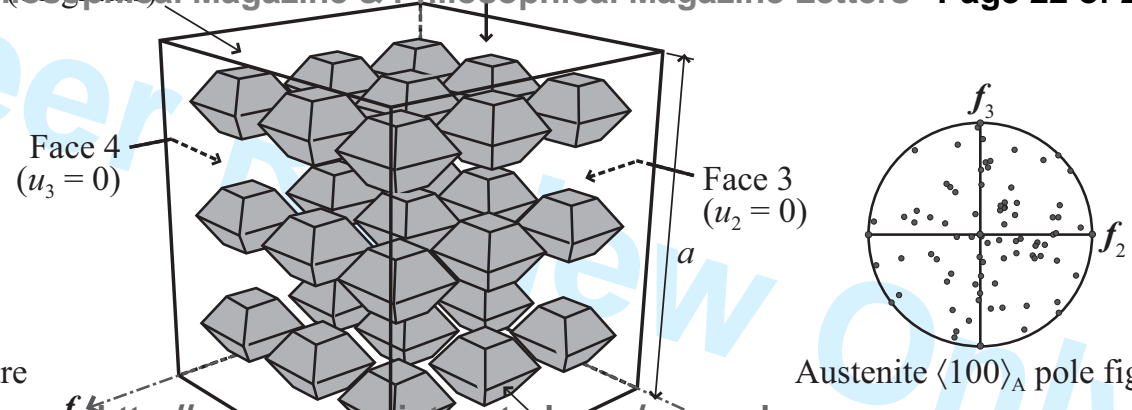

9

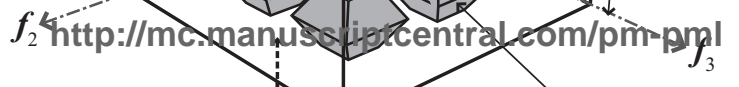

Austenite $\langle 100\rangle_{\mathrm{A}}$ pole figure

Face $2\left(u_{1}=0\right)$

Austenitic inclusion (27 grains) 


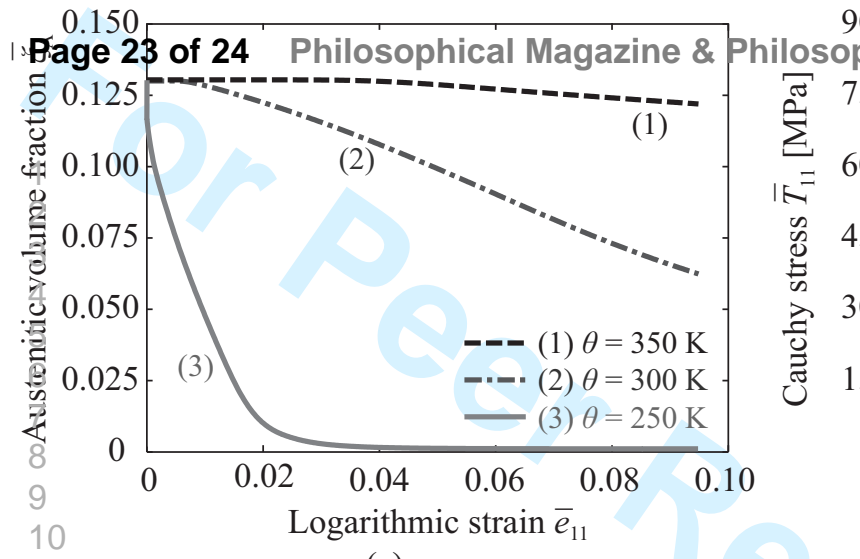

(a)

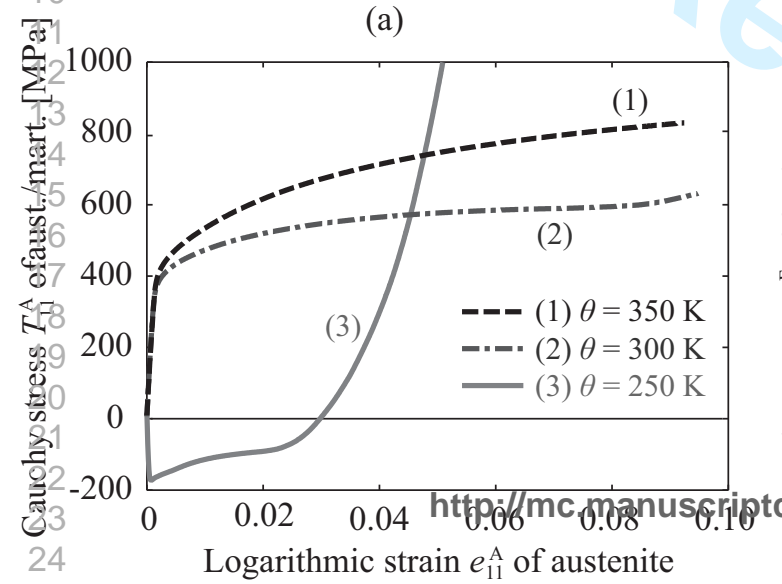

25
900

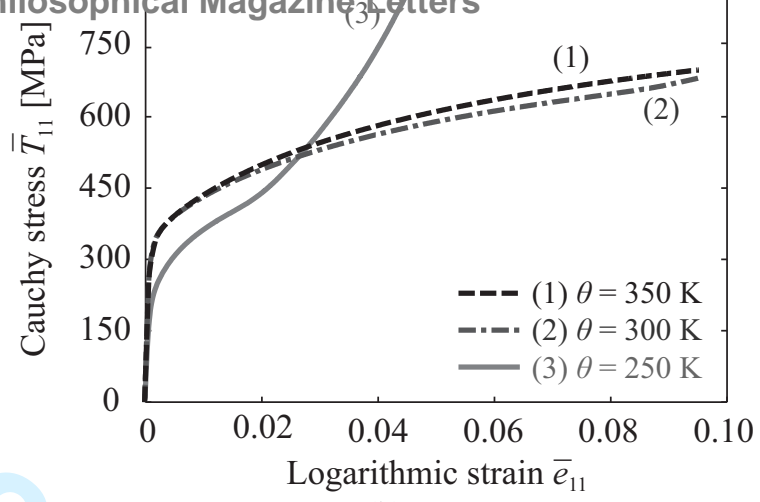

(b)

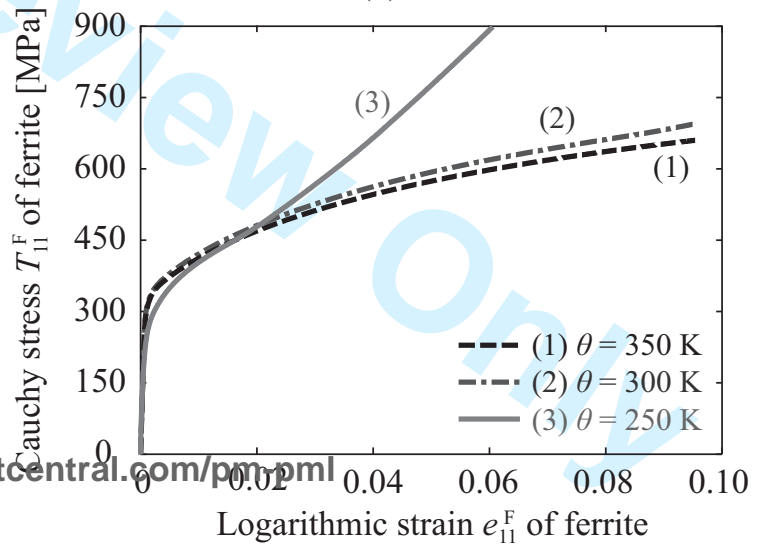

(d) 


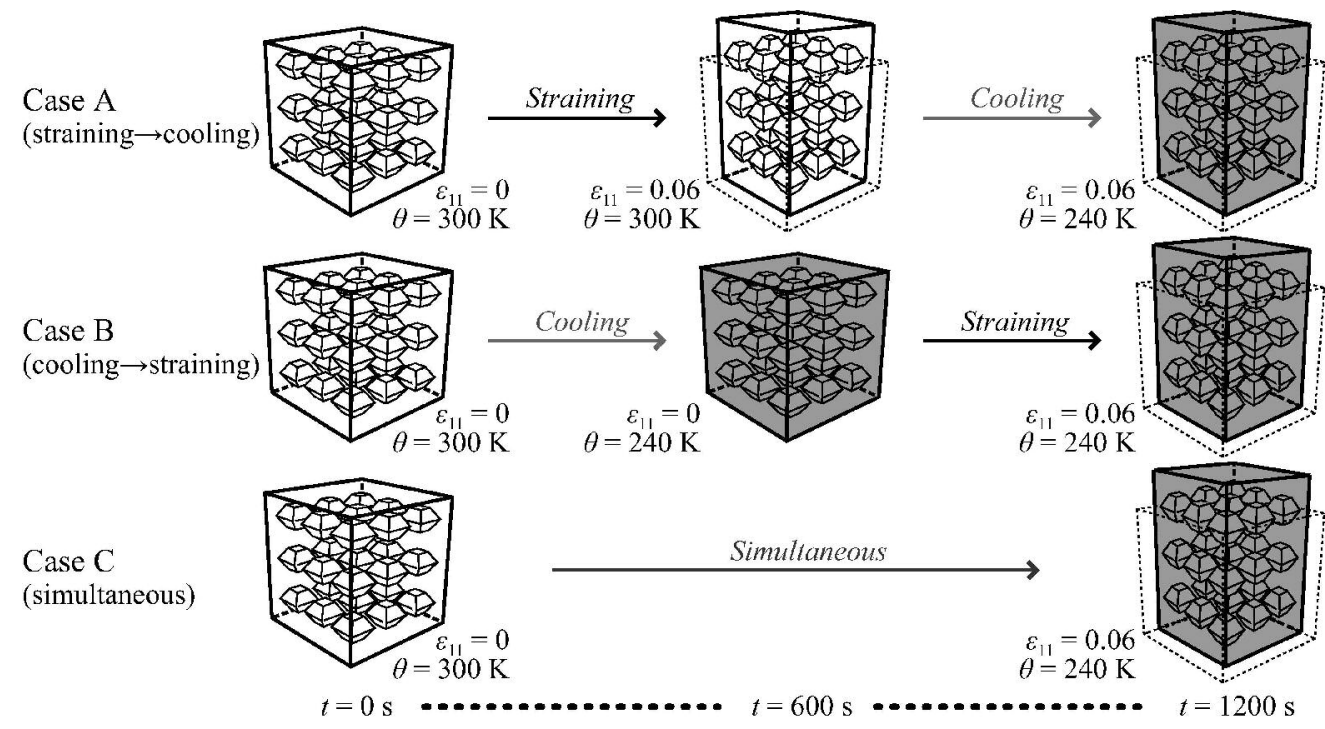

$141 \times 77 \mathrm{~mm}(600 \times 600 \mathrm{DPI})$ 

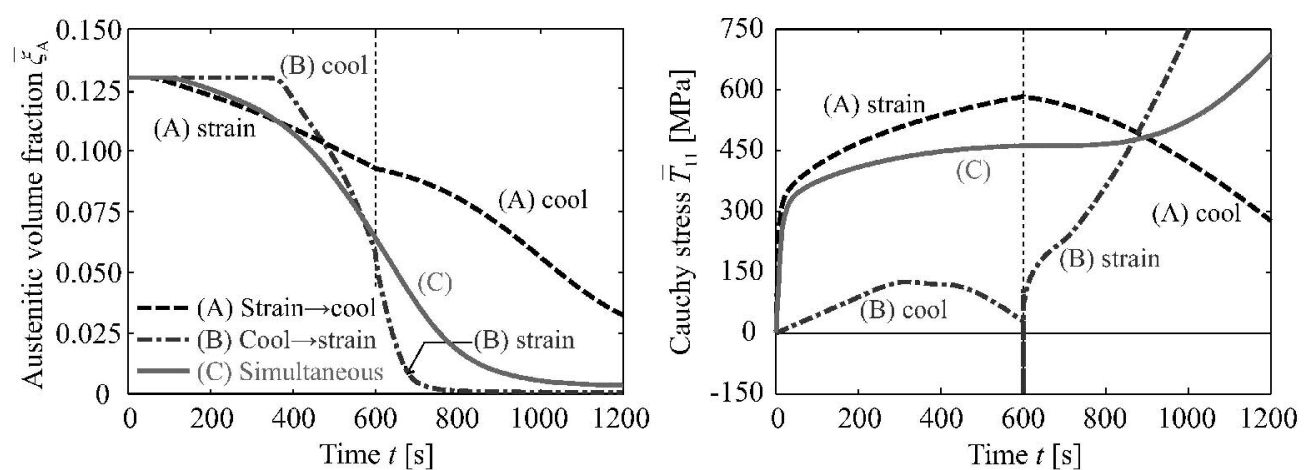

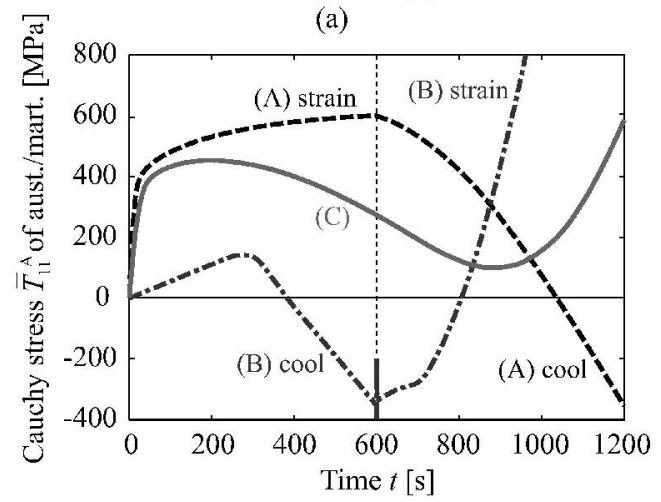

(c)

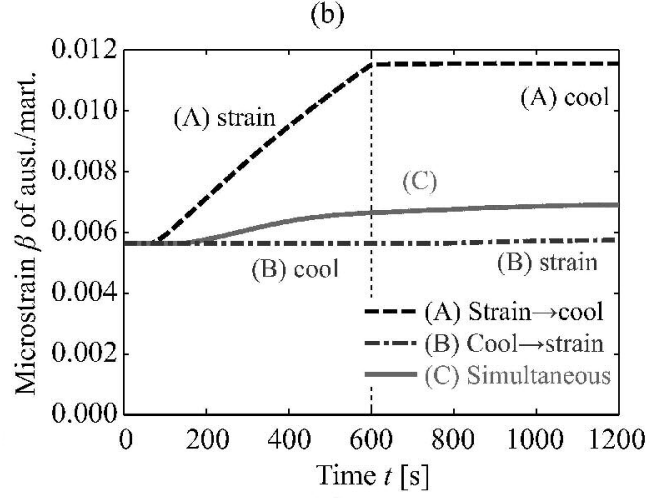

(d)

$155 \times 119 \mathrm{~mm}(600 \times 600 \mathrm{DPI})$ 